\title{
Detection of dimming/brightening in Italy from homogenized all-sky and clear-sky surface solar radiation records and underlying causes (1959-2013)
}

\author{
Veronica Manara $^{1,2}$, Michele Brunetti ${ }^{3}$, Angela Celozzi ${ }^{4}$, Maurizio Maugeri ${ }^{1,3}$, Arturo Sanchez-Lorenzo ${ }^{5}$, and \\ Martin Wild ${ }^{2}$ \\ ${ }^{1}$ Department of Physics, Università degli Studi di Milano, Milan, Italy \\ ${ }^{2}$ ETH Zurich, Institute for Atmospheric and Climate Science, Zurich, Switzerland \\ ${ }^{3}$ Institute of Atmospheric Sciences and Climate, ISAC-CNR, Bologna, Italy \\ ${ }^{4}$ Italian Air Force, COMET Centro Operativo per la Meteorologia, Pratica di Mare (RM), Italy \\ ${ }^{5}$ Instituto Pirenaico de Ecología, Consejo Superior de Investigaciones Científicas (IPE-CSIC), Zaragoza, Spain
}

Correspondence to: Veronica Manara (veronica.manara@unimi.it)

Received: 9 March 2016 - Published in Atmos. Chem. Phys. Discuss.: 24 May 2016

Revised: 22 July 2016 - Accepted: 17 August 2016 - Published: 8 September 2016

\begin{abstract}
A dataset of 54 daily Italian downward surface solar radiation (SSR) records has been set up collecting data for the 1959-2013 period. Special emphasis is given to the quality control and the homogenization of the records in order to ensure the reliability of the resulting trends. This step has been shown as necessary due to the large differences obtained between the raw and homogenized dataset, especially during the first decades of the study period. In addition, SSR series under clear-sky conditions were obtained considering only the cloudless days from corresponding ground-based cloudiness observations. Subsequently, records were interpolated onto a regular grid and clustered into two regions, northern and southern Italy, which were averaged in order to get all-sky and clear-sky regional SSR records. Their temporal evolution is presented, and possible reasons for differences between all-sky and clear-sky conditions and between the two regions are discussed in order to determine to what extent SSR variability depends on aerosols or clouds. Specifically, the all-sky SSR records show a decrease until the mid1980s (dimming period), and a following increase until the end of the series (brightening period) even though strength and persistence of tendencies are not the same in all seasons. Clear-sky records present stronger tendencies than all-sky records during the dimming period in all seasons and during the brightening period in winter and autumn. This suggests that, under all-sky conditions, the variations caused by the increase/decrease in the aerosol content have been par-
\end{abstract}

tially masked by cloud cover variations, especially during the dimming period. Under clear sky the observed dimming is stronger in the south than in the north. This peculiarity could be a consequence of a significant contribution of mineral dust variations to the SSR variability.

\section{Introduction}

The fraction of solar radiation that reaches the Earth's surface is the source of energy which drives the majority of the processes in the atmosphere and in the oceans and plays a crucial role in a large number of sectors (e.g., agriculture, tourism, solar energy production) (Hartmann et al., 1986; Wild, 2009, 2012). For these reasons, it is very important to study the spatial distribution and the temporal behavior of surface solar radiation (SSR). Continuous observations by thermoelectric pyranometers at the Earth's surface date back to the 1920s, for example at the Stockholm site since 1923 (Stanhill, 1983; Wild et al., 2009). Surface radiation measurements started to become available on a widespread basis only in the late 1950s, with the establishment of numerous radiation sites during the International Geophysical Year (IGY) 1957-1958.

Studies of the last decades have demonstrated that SSR has not been constant over time (Dutton et al., 1991; Liepert 
et al., 1994; Ohmura and Lang, 1989; Russak, 1990; Stanhill and Moreshet, 1992), as shown by decadal fluctuations which exceed the accuracy limit of observational irradiance measurements (2\% on an annual basis) (Gilgen et al., 1998). They report a decrease in SSR, "global dimming", of about 3-9 $\mathrm{W} \mathrm{m}^{-2}$ from the 1950 s to the 1980 s and a subsequent increase, "brightening", of about $1-4 \mathrm{~W} \mathrm{~m}^{-2}$ from the beginning of the 1980s (Wild, 2012). These two periods are highlighted not only by studies focusing on specific regions (Liang and Xia, 2005; Long et al., 2009; Sanchez-Lorenzo and Wild, 2012; Sanchez-Lorenzo et al., 2013, 2015; Wang and Yang, 2014) but also by studies focusing on worldwide datasets (Alpert et al., 2005; Gilgen et al., 1998; Liepert, 2002; Stanhill and Cohen, 2001; Wang et al., 2012; Wild et al., 2005, 2009).

The causes of these decadal variations are not completely clear: it has been suggested that changes in the anthropogenic aerosols and cloud cover can be major causes (e.g., Liepert et al., 1994; Stanhill and Cohen, 2001; Wild, 2009, 2016), while changes in radiatively active gas concentrations have, at least at the global scale, a minor effect (Kvalevåg and Myhre, 2007; Romanou et al., 2007). Aerosols and clouds can interact in various ways and are therefore not completely independent (Ramanathan et al., 2001). Aerosols act as a modulator of SSR by absorption or scattering of solar radiation (direct effect) (Radke et al., 1989; Twomey et al., 1984) and by changing the number of cloud condensation nuclei particles (indirect aerosol effect) that also change albedo and cloud lifetime (Albrecht, 1989; Lohmann and Feichter, 2005). The increase in anthropogenic aerosol emissions in the 20th century is thought to have been the major cause of the observed decadal SSR reduction until the 1980s (e.g., Liepert and Tegen, 2002; Norris and Wild, 2007; Stanhill and Cohen, 2001), while measures to reduce air pollution in the late 20th century are possibly responsible for the renewed increase in SSR (Chiacchio and Wild, 2010; Dutton et al., 2004, 2006; Hansen et al., 1997; Nabat et al., 2014). Nevertheless, the relative contribution of clouds and aerosols is not yet clear, especially after comparing studies regarding different areas.

For these reasons, it is interesting to understand to what extent the SSR variability depends on aerosol variations or on changes in cloud characteristics. Different studies have tried to estimate this distinction by using global climate models, satellite-derived products and ground-based observations, finding a good agreement between clear-sky SSR variations and changes in aerosol emissions and concentrations, indicating aerosols as a major contributor to SSR variability at decadal scale (Wild, 2016). In addition, some studies analyzing all-sky SSR have highlighted the important contribution of clouds especially at an interannual scale (Folini and Wild, 2011; Mateos et al., 2014; Norris and Wild, 2007; Parding et al., 2014; Xia, 2010a, b). Other studies confirmed that changes in aerosols play a major role in the decadal variations in SSR (Li et al., 2007; Zhang et al., 2015), although there is a tendency to underestimate the dimming and brightening obtained with models with respect to trends obtained with ground-based observations. This has been attributed to possible deficiencies in aerosol emission inventories or an underestimation of aerosol direct radiative forcing (Allen et al., 2013; Cherian et al., 2014; Folini and Wild, 2011; Ruckstuhl and Norris, 2009). As concerns the aerosol radiative forcing, some studies have tried to analyze the problem combining SSR series with optical depth and aerosol concentration observations, finding a comparable or higher contribution of the direct aerosol effect with respect to the indirect aerosol effect (Nabat et al., 2014, 2015; Ohmura, 2009; Ruckstuhl et al., 2008; Turnock et al., 2015). However, few studies have used only ground-based observations to obtain clear-sky and all-sky SSR series in order to investigate the aerosol-cloud effect (Liang and Xia, 2005; Liepert, 2002; Long et al., 2009; Ruckstuhl et al., 2008; Wild et al., 2005); this is due to the difficulty in recovering hightemporal-resolution SSR series together with additional information on cloudiness or direct/diffuse radiation to discriminate clear-sky conditions (Long and Ackerman, 2000; Wild, 2009).

In Italy, there have been no studies on the temporal evolution of SSR and its relation to aerosol concentrations and cloud cover variability. The best available information concerns sunshine duration (SD) for the 1936-2013 period (Manara et al., 2015). It shows an increasing tendency starting in the 1980s preceded by a less evident decreasing tendency. Comparing these trends with corresponding cloud amount series, Manara et al. (2015) found that the expected negative correlation of these two variables is often not evident. This suggested that during the global dimming/brightening periods there is an important fraction of SD evolution that cannot be explained by cloud cover changes which must therefore depend on other factors such as changes in aerosol optical thickness. The temporal variations in aerosol optical thickness of the last decades seem to be mainly driven by anthropogenic emissions (Streets et al., 2006, 2009), even though, especially for southern Italy, mineral particles originating from Sahara and Sahel areas may also have a significant role, as recently suggested for Spain by Sanchez-Romero et al. (2016). This natural atmospheric aerosol, with emissions that are highly variable from year to year, is a significant component of the Mediterranean area (Pey et al., 2013; Varga et al., 2014) causing reflection and absorption of the incoming solar radiation and therefore affecting the energy balance together with anthropogenic aerosols (Zhu et al., 2007).

In this context, this work aims at collecting, quality checking, homogenizing (Sect. 2) and analyzing an extensive database of Italian SSR records in order to obtain average regional series under both all-sky (Sect. 3.1) and clear-sky conditions (Sect. 3.2). By doing this, we want to describe how SSR has changed in Italy during about the last 60 years and to explain how these variations depend on aerosols or cloud variability (Sects. 3.3, 4). 


\section{Data and data preprocessing}

\subsection{Data}

The Italian SSR series used in this work were obtained at daily scale from the Italian Air Force stations (AM, Aeronautica Militare, 29 series - 1959-2013 period) and from the National Agro-meteorological Database (BDAN, Banca Dati Agrometeorologica Nazionale, 19 series - 19942013 period). Some information about the history of the AM observations are available in a report of the Italian Air Force (2012) and the data for the 1964-2013 period are also available in the World Radiation Data Centre (WRDC) of the Main Geophysical Observatory in St. Petersburg. In order to increase data availability, especially for the Alpine region, we considered also the series from the meteorological observatory of Trieste (1971-2013 period) (Stravisi and Cirilli, 2014) and five series from Switzerland, close to the Italian border, from the Swiss Federal Office of Meteorology and Climatology (MeteoSwiss - 1981-2013 period).

The data that come from the AM stations and from the meteorological observatory of Trieste were recorded with a Robitzsch bimetallic actinograph until the 1980s. This instrument was then replaced with the Kipp \& Zonen CM11 pyranometer in the first case and with different types of Kipp \& Zonen CM pyranometers in the second one (for more details about AM instruments and instrument changes, see http://wrdc.mgo.rssi.ru/; for more details about Trieste instruments, see Stravisi, 2004). The CM11 pyranometer was also used in the stations included in the BDAN database, with the only exception of two stations that used a Middleton EP07 pyranometer. Finally, the data that come from MeteoSwiss were measured with a Kipp \& Zonen CM21 pyranometer.

The main difference between the Robitzsch bimetallic actinograph and the Kipp \& Zonen pyranometer is that the measure is mechanical in the first case and thermoelectrical in the second. Specifically, the Robitzsch pyranometer consists of a black metallic strip located between two white metallic strips. Due to differential absorption, a temperature difference is created between the strips which serves as a measure of radiation intensity. This temperature difference drives the position of a pen which allows recording of radiation intensity on a paper strip chart. The sensitivity range covers the entire spectrum of solar radiation; only radiation above $2 \mu \mathrm{m}$ is not included - this, however, contributes only very little to the solar irradiance.

The Kipp \& Zonen and Middleton pyranometers are based on a black-coated surface which is warmed up by solar radiation. The thermal energy is converted into measurable voltage, which is used to measure the solar irradiance. These pyranometers are provided with an automatic acquisition system which allows for recording of solar irradiance on a digital support. The spectral range covers the interval of $0.3-$ $2.8 \mu \mathrm{m}$.

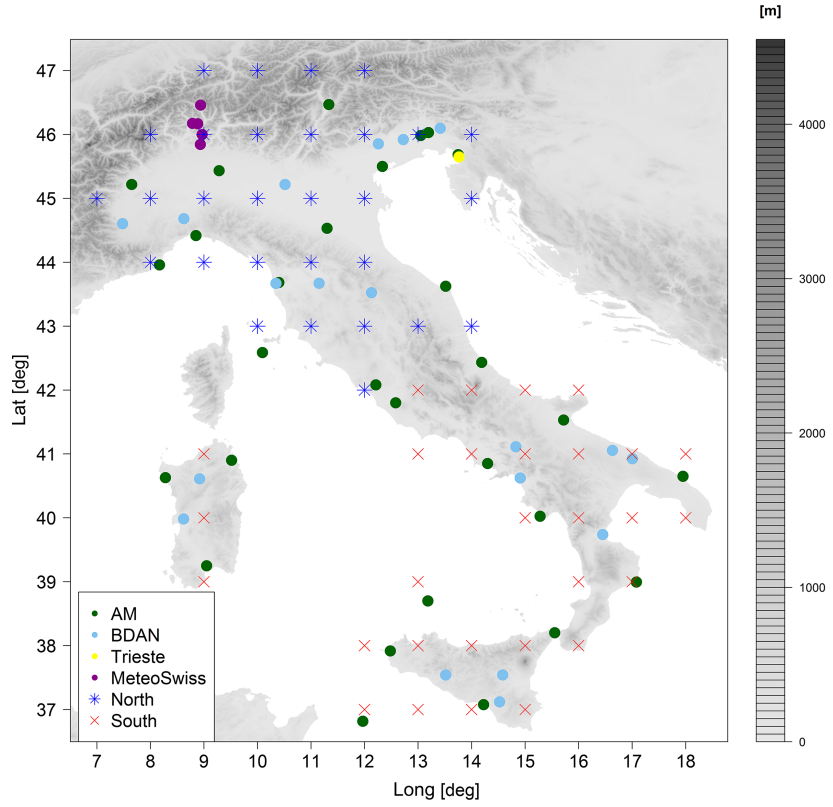

Figure 1. Spatial distribution of the stations and of the grid-mode version of the dataset (see Sect. 2.3): stars and crosses represent, respectively, northern ( 29 points) and southern ( 29 points) Italian grid points as clustered by a principal component analysis. The figure also shows the orography of the region and gives evidence of the sources of the station records, with green circles for AM series (29 series), blue circles for BDAN series (19 series), a yellow circle for the Trieste observatory and violet circles for MeteoSwiss series (5 series).

The final dataset is composed of 54 daily series with data for the 1959-2013 period. All series have at least 15 years of data (Fig. 1 and Table 1). The spatial distribution of the stations and the length of the series in relation to their location is uniform, the only exception are the series in the Alps and Apennines. All series are located in the plains and coastal areas with elevation lower than $600 \mathrm{~m}$. Data availability vs. time is rather inhomogeneous with a minimum before the beginning of the period covered by the BDAN series (Fig. 2).

\subsection{Data homogenization, gap filling and anomaly records}

Before analyzing the time evolution of SSR, we subjected the records to a quality check and to a homogenization procedure. A quality check was performed at a daily timescale in order to find out and correct gross errors (Aguilar et al., 2003). Specifically, we searched for negative values and values exceeding the radiation at the top of the atmosphere. In addition, the reliability of station coordinates was checked by means of the comparison with station metadata and checking the elevation in relation to position. After the quality check, monthly series were calculated when the proportion of missing data did not exceed $20 \%$. 
Table 1. Details on the network, station location, instruments and length of the records in the SSR dataset. The last column shows which records have been considered to calculate the regional mean under clear-sky conditions (see Sect. 2.4).

\begin{tabular}{|c|c|c|c|c|c|c|c|c|c|}
\hline $\begin{array}{l}\text { Network/data } \\
\text { source }\end{array}$ & $\begin{array}{l}\text { Station } \\
\text { name }\end{array}$ & Country & Region & $\begin{array}{r}\text { Latitude } \\
\text { (deg.) }\end{array}$ & $\begin{array}{r}\text { Longitude } \\
\text { (deg.) }\end{array}$ & $\begin{array}{r}\text { Elevation } \\
(\mathrm{m})\end{array}$ & Period & $\begin{array}{l}\text { Instrument } \\
\text { (pyranograph, } \\
\text { pyranometer) }\end{array}$ & $\begin{array}{l}\text { Selected } \\
\text { clear sky } \\
0 \text { okta }\end{array}$ \\
\hline MeteoSwiss & $\begin{array}{l}\text { Acquarossa } \\
\text { Comprovasco }\end{array}$ & $\mathrm{CH}$ & $\mathrm{N}$ & 46.459 & 8.936 & 575 & 1988-2013 & Kipp \& Zonen CM21 & $\mathrm{N}$ \\
\hline AM & Alghero & I & $\mathrm{S}$ & 40.630 & 8.280 & 23 & 1959-1989 & Robitzsch & $\mathrm{N}$ \\
\hline AM & Amendola & I & $\mathrm{S}$ & 41.530 & 15.720 & 57 & $1959-2010$ & $\begin{array}{l}\text { Robitzsch and Kipp \& } \\
\text { Zonen CM11 }\end{array}$ & $\mathrm{Y}$ \\
\hline $\mathrm{AM}$ & $\begin{array}{l}\text { Ancona } \\
\text { Cappuccini }\end{array}$ & I & $\mathrm{N}$ & 43.623 & 13.516 & 104 & 1959-1978 & Robitzsch & $\mathrm{Y}$ \\
\hline $\mathrm{AM}$ & Bologna & I & $\mathrm{N}$ & 44.530 & 11.300 & 36 & 1959-1989 & Robitzsch & $\mathrm{Y}$ \\
\hline $\mathrm{AM}$ & Bolzano & I & $\mathrm{N}$ & 46.467 & 11.333 & 241 & $1959-1988$ & Robitzsch & $\mathrm{Y}$ \\
\hline AM & Brindisi & I & $\mathrm{S}$ & 40.650 & 17.950 & 15 & $1959-2013$ & $\begin{array}{l}\text { Robitzsch and Kipp \& } \\
\text { Zonen CM11 }\end{array}$ & $\mathrm{Y}$ \\
\hline $\mathrm{AM}$ & $\begin{array}{l}\text { Cagliari } \\
\text { Elmas }\end{array}$ & I & S & 39.250 & 9.050 & 4 & 1959-2013 & $\begin{array}{l}\text { Robitzsch and Kipp \& } \\
\text { Zonen CM11 }\end{array}$ & $\mathrm{N}$ \\
\hline $\mathrm{AM}$ & Capo Mele & I & $\mathrm{N}$ & 43.958 & 8.170 & 220 & $1964-2003$ & $\begin{array}{l}\text { Robitzsch and Kipp \& } \\
\text { Zonen CM11 }\end{array}$ & $\mathrm{Y}$ \\
\hline AM & Capo Palinuro & I & S & 40.025 & 15.280 & 184 & 1959-2013 & $\begin{array}{l}\text { Robitzsch and Kipp \& } \\
\text { Zonen CM11 }\end{array}$ & $\mathrm{Y}$ \\
\hline UCEA-BDAN & Carpeneto & I & $\mathrm{N}$ & 44.681 & 8.624 & 230 & 1994-2013 & Kipp \& Zonen CM11 & $\mathrm{Y}$ \\
\hline UCEA-BDAN & Chilivani & I & $\mathrm{S}$ & 40.610 & 8.919 & 216 & 1994-2013 & Kipp \& Zonen CM11 & $\mathrm{N}$ \\
\hline UCEA-BDAN & Cividale & I & $\mathrm{N}$ & 46.096 & 13.414 & 130 & 1997-2013 & Kipp \& Zonen CM11 & $\mathrm{Y}$ \\
\hline $\mathrm{AM}$ & Crotone & I & $\mathrm{S}$ & 38.996 & 17.080 & 155 & 1959-1989 & Robitzsch & $\mathrm{Y}$ \\
\hline UCEA-BDAN & Fiume Veneto & I & $\mathrm{N}$ & 45.920 & 12.724 & 19 & 1996-2013 & Kipp \& Zonen CM11 & $\mathrm{Y}$ \\
\hline $\mathrm{AM}$ & Gela & I & $\mathrm{S}$ & 37.076 & 14.225 & 33 & $1965-1997$ & $\begin{array}{l}\text { Robitzsch and Kipp \& } \\
\text { Zonen CM11 }\end{array}$ & $\mathrm{Y}$ \\
\hline AM & Genova Sestri & I & $\mathrm{N}$ & 44.417 & 8.850 & 2 & 1959-1989 & Robitzsch & $\mathrm{Y}$ \\
\hline UCEA-BDAN & Libertinia & I & $\mathrm{S}$ & 37.541 & 14.581 & 188 & 1994-2013 & Kipp \& Zonen CM11 & $\mathrm{N}$ \\
\hline MeteoSwiss & Locarno Monti & $\mathrm{CH}$ & $\mathrm{N}$ & 46.172 & 8.787 & 383 & $1981-2013$ & Kipp \& Zonen CM21 & $\mathrm{N}$ \\
\hline MeteoSwiss & Lugano & $\mathrm{CH}$ & $\mathrm{N}$ & 46.000 & 8.967 & 273 & $1981-2013$ & Kipp \& Zonen CM21 & $\mathrm{Y}$ \\
\hline MeteoSwiss & $\begin{array}{l}\text { Magadino } \\
\text { Cadenazzo }\end{array}$ & $\mathrm{CH}$ & $\mathrm{N}$ & 46.167 & 8.883 & 197 & $1981-2013$ & Kipp \& Zonen CM21 & $\mathrm{Y}$ \\
\hline $\mathrm{AM}$ & Messina & I & S & 38.201 & 15.553 & 59 & 1959-2006 & $\begin{array}{l}\text { Robitzsch and Kipp \& } \\
\text { Zonen CM11 }\end{array}$ & $\mathrm{Y}$ \\
\hline AM & Milano Linate & I & $\mathrm{N}$ & 45.433 & 9.283 & 107 & $1959-2010$ & $\begin{array}{l}\text { Robitzsch and Kipp \& } \\
\text { Zonen CM11 }\end{array}$ & $\mathrm{Y}$ \\
\hline AM & Napoli & I & $\mathrm{S}$ & 40.850 & 14.300 & 88 & 1959-1989 & Robitzsch & $\mathrm{Y}$ \\
\hline $\mathrm{AM}$ & Olbia & I & $\mathrm{S}$ & 40.900 & 9.517 & 13 & 1959-1988 & Robitzsch & $\mathrm{Y}$ \\
\hline UCEA-BDAN & Palo del Colle & I & S & 41.055 & 16.632 & 191 & 1994-2013 & Middleton EP07 & $\mathrm{Y}$ \\
\hline $\mathrm{AM}$ & Pantelleria Isola & I & S & 36.817 & 11.967 & 191 & 1959-2009 & $\begin{array}{l}\text { Robitzsch and Kipp \& } \\
\text { Zonen CM11 }\end{array}$ & $\mathrm{N}$ \\
\hline AM & Pescara & I & $\mathrm{S}$ & 42.433 & 14.189 & 10 & 1959-1987 & Robitzsch & $\mathrm{Y}$ \\
\hline UCEA-BDAN & Piano Cappelle & I & $\mathrm{S}$ & 41.113 & 14.827 & 152 & 1994-2013 & Kipp \& Zonen CM11 & $\mathrm{Y}$ \\
\hline $\mathrm{AM}$ & Pianosa Isola & I & $\mathrm{N}$ & 42.586 & 10.094 & 27 & 1959-1979 & Robitzsch & $\mathrm{Y}$ \\
\hline UCEA-BDAN & Pietranera & I & $\mathrm{S}$ & 37.541 & 13.517 & 158 & 1994-2013 & Kipp \& Zonen CM11 & $\mathrm{Y}$ \\
\hline $\mathrm{AM}$ & Pisa San Giusto & I & $\mathrm{N}$ & 43.683 & 10.400 & 2 & 1959-2013 & $\begin{array}{l}\text { Robitzsch and Kipp \& } \\
\text { Zonen CM11 }\end{array}$ & $\mathrm{Y}$ \\
\hline UCEA-BDAN & Piubega & I & $\mathrm{N}$ & 45.217 & 10.514 & 38 & $1997-2013$ & Kipp \& Zonen CM11 & $\mathrm{Y}$ \\
\hline UCEA-BDAN & Pontecagnano & I & $\mathrm{S}$ & 40.623 & 14.911 & 38 & $1997-2013$ & Kipp \& Zonen CM11 & $\mathrm{Y}$ \\
\hline $\mathrm{AM}$ & Roma Ciampino & I & S & 41.800 & 12.583 & 129 & 1959-2009 & $\begin{array}{l}\text { Robitzsch and Kipp \& } \\
\text { Zonen CM11 }\end{array}$ & $\mathrm{Y}$ \\
\hline UCEA-BDAN & San Casciano & I & $\mathrm{N}$ & 43.670 & 11.151 & 230 & 1994-2013 & Kipp \& Zonen CM11 & $\mathrm{Y}$ \\
\hline UCEA-BDAN & $\begin{array}{l}\text { San Piero } \\
\text { a Grado }\end{array}$ & I & $\mathrm{N}$ & 43.668 & 10.346 & 3 & 1994-2013 & Kipp \& Zonen CM11 & $\mathrm{Y}$ \\
\hline UCEA-BDAN & Santa Fista & I & $\mathrm{N}$ & 43.523 & 12.130 & 311 & 1994-2013 & Kipp \& Zonen CM11 & $\mathrm{Y}$ \\
\hline UCEA-BDAN & Santa Lucia & I & $\mathrm{S}$ & 39.982 & 8.620 & 14 & 1994-2013 & Kipp \& Zonen CM11 & $\mathrm{N}$ \\
\hline UCEA-BDAN & Santo Pietro & I & $\mathrm{S}$ & 37.120 & 14.525 & 313 & 1994-2013 & Kipp \& Zonen CM11 & $\mathrm{Y}$ \\
\hline UCEA-BDAN & Sibari & I & $\mathrm{S}$ & 39.738 & 16.449 & 10 & 1994-2013 & Kipp \& Zonen CM11 & $\mathrm{Y}$ \\
\hline MeteoSwiss & Stabio & $\mathrm{CH}$ & $\mathrm{N}$ & 45.843 & 8.932 & 353 & 1981-2013 & Kipp \& Zonen CM21 & $\mathrm{Y}$ \\
\hline UCEA-BDAN & Susegana & I & $\mathrm{N}$ & 45.853 & 12.258 & 67 & 1994-2013 & Middleton EP07 & $\mathrm{Y}$ \\
\hline
\end{tabular}


Table 1. Continued.

\begin{tabular}{|c|c|c|c|c|c|c|c|c|c|}
\hline $\begin{array}{l}\text { Network/data } \\
\text { source }\end{array}$ & $\begin{array}{l}\text { Station } \\
\text { name }\end{array}$ & Country & Region & $\begin{array}{r}\text { Latitude } \\
\text { (deg.) }\end{array}$ & $\begin{array}{r}\text { Longitude } \\
\text { (deg.) }\end{array}$ & $\begin{array}{r}\text { Elevation } \\
(\mathrm{m})\end{array}$ & Period & $\begin{array}{l}\text { Instrument } \\
\text { (pyranograph, } \\
\text { pyranometer) }\end{array}$ & $\begin{array}{l}\text { Selected } \\
\text { clear sky } \\
0 \text { okta }\end{array}$ \\
\hline AM & Torino Caselle & I & $\mathrm{N}$ & 45.217 & 7.650 & 301 & 1959-1985 & Robitzsch & $\mathrm{Y}$ \\
\hline AM & Trapani Birgi & I & $\mathrm{S}$ & 37.917 & 12.483 & 7 & 1959-1996 & $\begin{array}{l}\text { Robitzsch and Kipp \& } \\
\text { Zonen CM11 }\end{array}$ & $\mathrm{N}$ \\
\hline AM & Trieste & I & $\mathrm{N}$ & 45.683 & 13.750 & 4 & 1959-2001 & $\begin{array}{l}\text { Robitzsch and Kipp \& } \\
\text { Zonen CM11 }\end{array}$ & Y \\
\hline Observatory of Trieste & Trieste Hortis & I & $\mathrm{N}$ & 45.648 & 13.766 & 35 & 1971-2013 & $\begin{array}{l}\text { Robitzsch and Kipp \& } \\
\text { Zonen CM }\end{array}$ & $\mathrm{Y}$ \\
\hline UCEA-BDAN & Turi & I & $\mathrm{S}$ & 40.924 & 17.005 & 230 & 1994-2013 & Middleton EP07 & $\mathrm{N}$ \\
\hline $\mathrm{AM}$ & $\begin{array}{l}\text { Udine } \\
\text { Campoformido }\end{array}$ & I & $\mathrm{N}$ & 46.029 & 13.196 & 94 & 1959-1978 & Robitzsch & $\mathrm{Y}$ \\
\hline AM & Udine Rivolto & I & $\mathrm{N}$ & 45.983 & 13.050 & 51 & 1964-2010 & $\begin{array}{l}\text { Robitzsch and Kipp \& } \\
\text { Zonen CM11 }\end{array}$ & $\mathrm{Y}$ \\
\hline $\mathrm{AM}$ & Ustica Isola & I & $\mathrm{S}$ & 38.700 & 13.183 & 250 & 1959-1997 & $\begin{array}{l}\text { Robitzsch and Kipp \& } \\
\text { Zonen CM11 }\end{array}$ & $\mathrm{Y}$ \\
\hline $\mathrm{AM}$ & Venezia Tessera & I & $\mathrm{N}$ & 45.500 & 12.333 & 2 & 1959-1989 & Robitzsch & Y \\
\hline UCEA-BDAN & Verzuolo & I & $\mathrm{N}$ & 44.603 & 7.480 & 420 & 1995-2013 & Kipp \& Zonen CM11 & $\mathrm{Y}$ \\
\hline $\mathrm{AM}$ & Vigna di Valle & I & $\mathrm{N}$ & 42.081 & 12.211 & 275 & 1959-2013 & $\begin{array}{l}\text { Robitzsch and Kipp \& } \\
\text { Zonen CM11 }\end{array}$ & $\mathrm{Y}$ \\
\hline
\end{tabular}

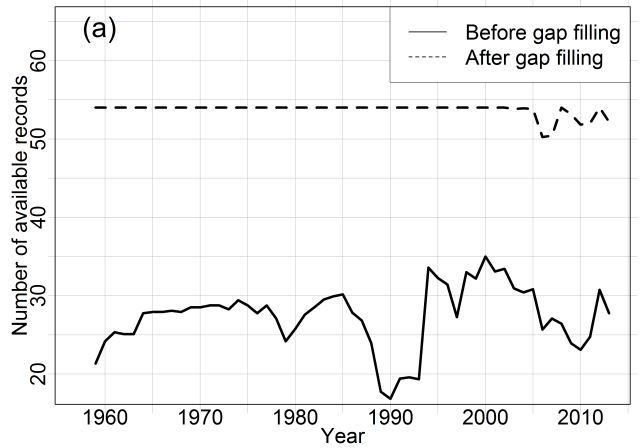

(b)

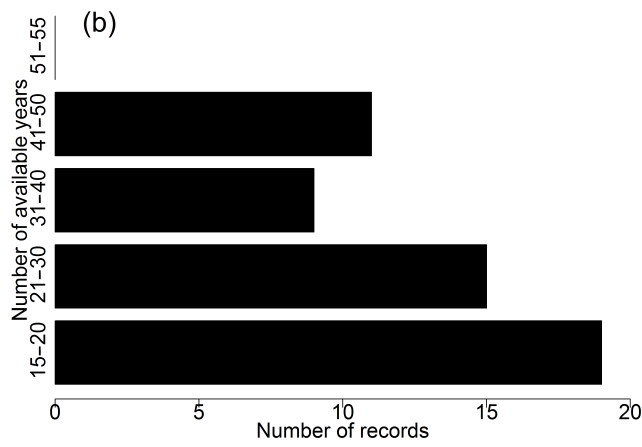

Figure 2. (a) Temporal evolution of the number of available records per year before (bold line) and after the gap-filling procedure (dashed line) (see Sect. 2.2); (b) the histogram shows the number of records as a function of the number of available years before the gap-filling procedure.

All monthly records were subjected to homogenization in order to identify and eliminate non-climatic signals (Aguilar et al., 2003; Brunetti et al., 2006b). Our aim was to identify time-dependent adjusting factors in order to transform the original records into homogeneous ones. The homogenization of the series was performed using a procedure based on a relative homogeneity test (Brunetti et al., 2006b) based on statistical methods supported by metadata information. Specifically, each test series is compared against 10 other reference series that correlate well with the test series by means of the Craddock test (Craddock, 1979). This methodology is suitable to calculate correcting factors, but the identification of an inhomogeneity is not always easy and unambiguous (Brunetti et al., 2006b). For this reason, we homogenize a period only when more reference series give coherent adjustment estimates. In this way, we can be more confident that the inhomogeneity is "real" and ascribable to the test series and not to the reference series. The reference series that result homogeneous in a sufficiently long sub-period centered on the break year are then selected to estimate the adjustments. We use several series to estimate the adjustments to increase their stability and to avoid unidentified outliers in the reference series from producing wrong corrections. By comparing the obtained breaks of each series with the corresponding metadata, we found in most of the cases a reasonable agreement between the breaks identified by the statistical method with information reported by metadata.

The common variance between two stations depends on their distance, and for the Italian territory, as previously found for SD (Manara et al., 2015), it falls to $50 \%$ at a distance of about $150 \mathrm{~km}$. Homogenization was performed at a monthly timescale. However, a daily version of the adjustments was also generated in order to homogenize the daily series.

All analyzed series showed at least one inhomogeneous period highlighting the importance of homogenization, especially before 1980 . The most relevant inhomogeneities fall in the first 20 years of the investigated period, where many 
instrument changes and recalibrations occurred, whereas the inhomogeneities are less relevant from the 1980s when the Robitzsch pyranograph was replaced in all AM stations by the CM11 pyranometer (Table 1), an instrument with higher quality, as recommended by the WMO (Italian Air Force, 2012).

Figure 3a shows the Italian average annual SSR anomaly series (relative anomalies with respect to the period 19762005) before and after homogenization with corresponding Gaussian low-pass filters (11-year window; 3-year standard deviation) that allow a better visualization of the decadal variability and long-term trend, while Fig. $3 \mathrm{~b}$ shows the curve obtained by averaging the mean annual adjustments over all single records, together with their absolute range. The details on how we obtained regional SSR anomaly series will be explained in the following sections.

The average annual records before and after the homogenization show a different decadal variability during the 19591970 and 1971-1980 periods, where increasing (average adjustment: 1.098) and decreasing (average adjustment: 0.964) correcting factors, respectively, have been applied to the original series. However, during the 1981-2013 period the two series show a similar behavior, where in fact only small correcting factors have been applied to the original series (average adjustment: 1.008). Overall, the use of the raw series hides the trends obtained during the study period, especially before the 1980s when the dimming period observed in the homogenized series is not evident during the 1960s and early 1970s.

We filled the gaps in each monthly record using a procedure similar to that described in Manara et al. (2015). In particular, the median of a set of five estimated values, corresponding to the five highest correlated reference records, was selected in order to avoid outliers resulting from peculiar climatic conditions of the reference station. When fewer than five reference records fulfilling the requested conditions (distance within $500 \mathrm{~km}$ from the record under analysis and at least six monthly values in common with it in the month of the gap) were available, the median was calculated with the available reference series. After the gap-filling procedure, all series had at least $90 \%$ of available data during the 1959-2013 period and $99 \%$ during the 1976-2005 period (Fig. 2), used as the reference period to calculate the anomaly series. Therefore, all the series were transformed into monthly/seasonal/annual relative anomaly series with respect to the monthly/seasonal/annual 1976-2005 normals. Seasons are calculated according to the following scheme - December-January-February (winter), March-April-May (spring), June-July-August (summer), and September-October-November (autumn) - and the year is calculated for the December-November period. The winter season is dated to the year in which January and February fall, and, for the first year, the winter and the annual means are calculated using also the monthly mean of December 1958.

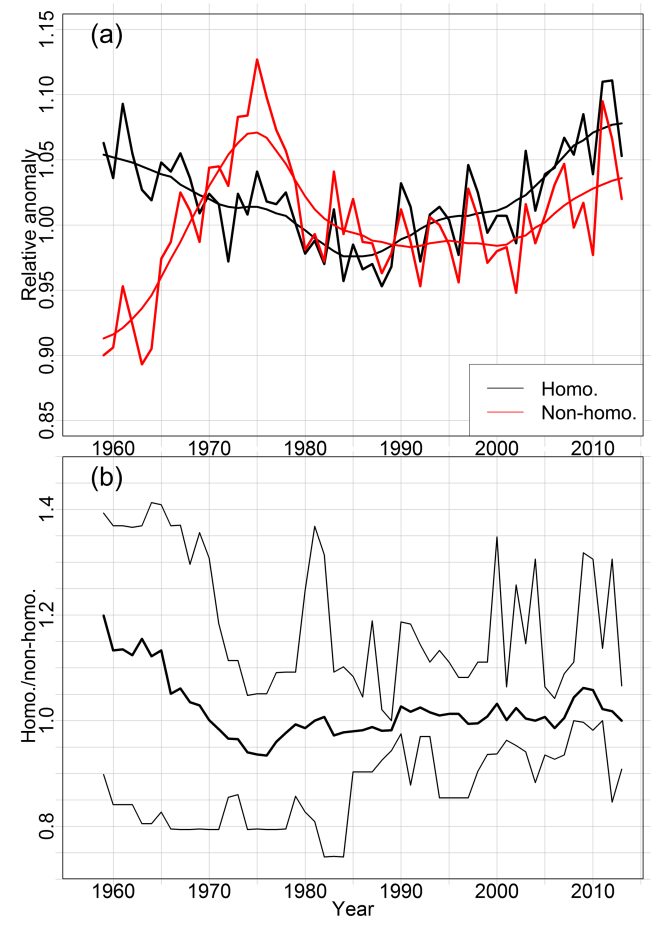

Figure 3. (a) Average annual Italian SSR series plotted together with an 11-year window, 3-year standard deviation Gaussian lowpass filter before (red line) and after (black line) the homogenization procedure; (b) mean annual adjustment series is obtained by calculating the annual average adjustment over all series (bold line). The figure also shows the maximum range in the adjustments.

\subsection{Gridding and regional average record}

Starting from the monthly/seasonal/annual anomaly series, we generated a gridded version of the anomaly series with a resolution of $1^{\circ} \times 1^{\circ}$ in order to balance the contribution of areas with a higher number of stations with the contribution of areas with a lower number of stations. This technique, explained in more detail by Brunetti et al. (2006b) and Manara et al. (2015), is based on an inverse distance weighting approach with the addition of an angular term to take into account the anisotropy in the spatial distribution of stations. The resulted grid spans from 7 to $18^{\circ} \mathrm{E}$ and from 37 to $47^{\circ} \mathrm{N}$, with 58 grid points over the Italian territory (Fig. 1).

Then, the monthly gridded anomaly records were subjected to a principal component analysis (PCA) in order to identify areas with similar SSR temporal variability. With this technique, it is possible to identify a small number of variables, which are linear functions of the original data and which maximize their explained variance (Preisendorfer, 1988; Wilks, 1995). The analysis focused on the 19762005 period, the same reference period used to calculate the anomaly series. The analysis shows that the first five eigenvectors have an eigenvalue greater than 1 and they explain more than $91 \%$ of the total variance of the dataset. Then, 
we selected to rotate the first two empirical orthogonal functions (EOFs), which are those that account for 59 and $23 \%$, respectively, of the original variance of the dataset, in order to obtain a more physically meaningful pattern (Von Storch, 1995). We decided to select these two EOFs because they account for $82 \%$ of the original variance while the other three only account for $9 \%$. This procedure allowed to divide the Italian territory into two regions: northern Italy (29 grid points) and southern Italy (29 grid points) (Fig. 1). Finally, we calculated the monthly, seasonal and annual mean anomaly series for the two regions by averaging all corresponding grid point anomaly records. From here on, we refer to these series as the SSR anomaly series obtained under all-sky conditions to distinguish them from the series presented in the next section (Sect. 2.4) obtained selecting only the clear-sky days.

\subsection{Clear-sky series}

Starting from the 54 homogenized daily SSR series presented in Sects. 2.1 and 2.2, we aimed at determining clear SSR days for the 1959-2013 period. For this purpose, we used an updated version (both for number of series and for series length) of the total cloud cover (TCC) database presented by Maugeri et al. (2001) as a reference to extract the clear-sky days. In particular, we considered only the days with a daily TCC mean of 0 okta. For the SSR series without a corresponding TCC series, we considered the data from nearby stations. The main limitation of the previous procedure is that the condition adopted to select clear-sky days ( 0 okta of TCC) often allows for a very low number of days to be selected. We therefore tried to apply a less restrictive condition and we also extracted the clear-sky days using 1 okta as the threshold. The average of clear-sky days per station and month is $9 \%$ for the 0 okta threshold and $18 \%$ for the 1 okta threshold. These fractions are however higher in summer when SSR is more important, reaching the maximum value in July with $17 \%$ of 0 okta days and $34 \%$ of days with less than 1 okta of TCC.

Then, the monthly mean was calculated when at least two clear-sky daily values were available in the considered month. After gap filling, the monthly/seasonal/annual relative anomaly series were obtained with respect to the 19762005 period using the same technique explained in Sect. 2.2. To calculate the anomaly series we considered only the series with at least $50 \%$ (for 0 okta) and $80 \%$ (for 1 okta) of available data in the 1976-2005 period after the gap filling. This reduced the series to 44 in the first case (Table 1). In the final step, we interpolated the anomaly series as described in Sect. 2.3 and obtained the regional anomaly series, for the two regions and the two thresholds, by averaging all corresponding grid point anomaly series.

\section{Results}

\subsection{Trend analysis of the all-sky SSR records}

The average northern and southern Italy annual and seasonal SSR records obtained under all-sky conditions are shown in Fig. 4, together with the same low-pass filter used in Fig. 3. In order to better understand the depth and the length of the tendencies showed in Fig. 4, we subjected the records to a running trend analysis (Brunetti et al., 2006a) estimating the trend slope of each sub-interval of at least 21 years by applying a linear regression. The results are shown in Fig. 5. Specifically, we represent the length of the period considered for the analysis ( $y$ axes) in relation to the starting year of the window that the trend refers to ( $x$ axes). Slopes are shown by means of the colors of the corresponding pixels, with large squares for trends with a significance level of $p \leq 0.1$ and small squares for trends with a significance level of $p>0.1$ (considered here statistically non-significant), with significance levels estimated by means of the Mann-Kendall nonparametric test (Sneyers, 1992).

At annual scale both regions show a decreasing tendency until the mid-1980s and a following increase until the end of the series, with a period of stabilization in the late 1990s. The trends of the two periods are comparable, especially in the southern region. In fact, the trend for the whole period under analysis (e.g., 1959-2013 period) is not statistically significant, as highlighted by the running trend analysis (Fig. 5). However, the intensity of the dimming is slightly higher for the south than the north, especially for some windows starting in the mid-1960s (e.g., about $-3 \%$ per decade for the north and about $-4 \%$ per decade for the south for the 1965 1985 period), while the brightening is more intense in the north especially for the windows starting in the mid-1980s (e.g., about $+4 \%$ per decade for the north and about $+2 \%$ per decade for the south for the 1980-2010 period).

For the winter season, the records show a well-defined behavior with a dimming and a following brightening only in the northern region, where the record shows statistically significant negative and positive tendencies for some periods starting in the 1960s and 1980s, respectively. However, the behavior is not well defined in the southern region, with a minimum in the mid-1980s and two secondary maxima during the 1970s and 1990s (Fig. 4). As a consequence, the series shows only some sub-periods with a statistically significant trend. These sub-periods are less than 35 years long, and they start in the 1960s with a negative sign and in late 1970 s/early 1980 s with a positive sign. There is also a window extending 21 years, starting in 1990, with a significant decreasing tendency ( $-4 \%$ per decade) (Fig. 5).

The spring season has a similar pattern to the annual one, with a clear negative-positive sequence and a period of stabilization during the second half of the 1990s for both northern and southern Italy. The records show a comparable dimming for the two regions for periods longer than 30 years with vari- 


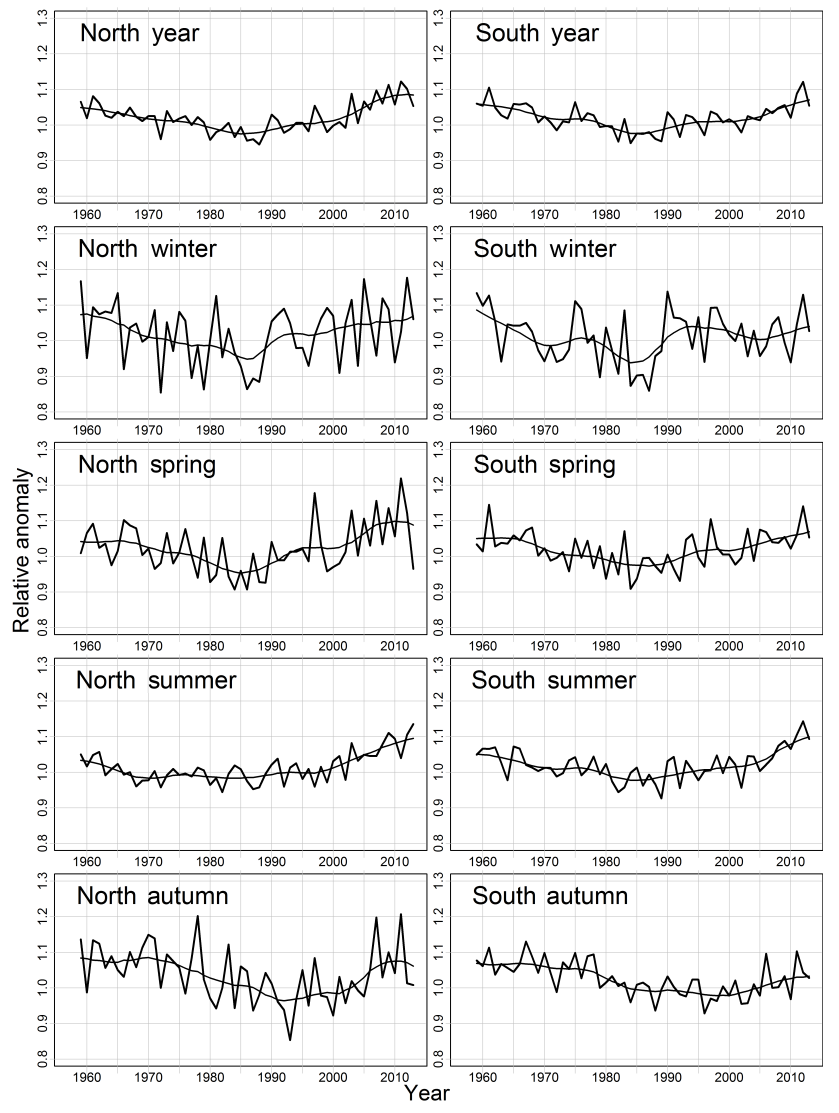

Figure 4. Average annual and seasonal northern (left column) and southern (right column) Italian SSR records obtained under all-sky conditions (bold lines), plotted together with an 11-year window, 3year standard deviation Gaussian low-pass filter (thin lines). The series are expressed as relative deviations from the 1976-2005 means.

ations of about $-3 \%$ per decade (e.g., 1962-1992 period), while it is slightly stronger in the north if sub-periods starting in the mid-1960s with fewer than 30 years are considered in which variations range between -7 and $-5 \%$ per decade. As concerns the brightening, it is stronger in the northern region, for both long and short sub-periods, with values of about $+6 \%$ per decade for some windows starting in the 1980s.

For the summer season the sequence of the dimming and brightening is evident and very similar to the annual and spring behavior only in the south. In the north, during the dimming period, there are only very few sub-periods with a significant decreasing trend, while in the south the most part of the windows starting in the 1960s have significant trends with variations of about $-3 \%$ per decade (e.g., 1960-1990 period), indicating a reduction of SSR. However, the brightening period is quite comparable for the two regions and reaches values of about $+4 \%$ per decade (e.g., 1983-2013 period). The trends of the longest periods are significant and

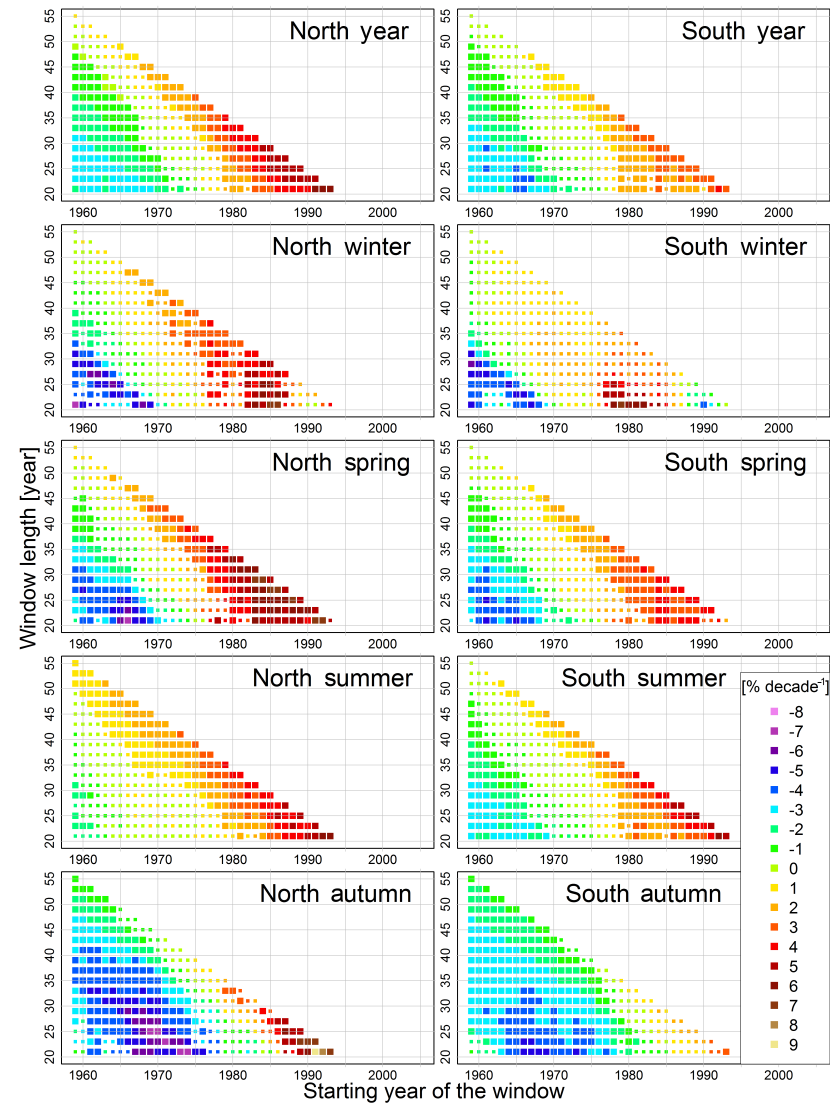

Figure 5. Running trend analysis for annual and seasonal northern (left column) and southern (right column) Italian SSR records obtained under all-sky conditions. The $y$ and $x$ axis represent the length and the first year of the period under analysis, respectively, while the colored pixels show the trend expressed in $\%$ decade $^{-1}$ with a significance level of $p \leq 0.1$ (large squares) and $p>0.1$ (small squares).

positive with values of about $+1 \%$ per decade (e.g., 19592013 period) only in the north as a consequence of its weaker dimming in the early period.

The autumn records (Fig. 4) start with a period without any trend for both regions and then show a decrease between the beginning of the 1970s and the beginning of the 1990s and a following increase, which is stronger in the northern than in the southern region. This picture is evident also in the running trends (Fig. 5), especially for the brightening period, where some sub-periods have a positive trend after the beginning of the 1980s in the north and none has a positive trend in the south, with the only exception of one 21-year sub-period starting in the 1990s. However, most of the subperiods starting in the 1960s and 1970s have significant and negative trends with values of about $-3 \%$ per decade. The trend over the whole period under analysis (1959-2013 period) is significant and negative for both regions with values of about $-2 \%$ per decade. 
Table 2. Absolute SSR trends in northern and southern Italy under all-sky conditions and estimated trends assuming no changes in cloudiness (see Sect. 3.3). The results concerning the dimming and brightening periods according to the northern and southern Italy annual records are highlighted in italic*.

\begin{tabular}{|c|c|c|c|c|c|c|}
\hline & & Year & Winter & Spring & Summer & Autumn \\
\hline \multirow[t]{7}{*}{ North all sky } & 1959-2013 & + & + & + & $3.1 \pm 0.8$ & $-1.5 \pm 0.7$ \\
\hline & 1959-1985 & $-4.4 \pm 0.8$ & $-3.0 \pm 1.3$ & $-7.2 \pm 2.2$ & $-3.9 \pm 1.6$ & $-3.5 \pm 1.9$ \\
\hline & 1986-2013 & $7.7 \pm 1.1$ & $3.2 \pm 1.3$ & $10.4 \pm 2.9$ & $12.3 \pm 1.9$ & $4.8 \pm 1.9$ \\
\hline & 1970-2013 & $2.9 \pm 0.7$ & $1.4 \pm 0.7$ & $4.8 \pm 1.5$ & $6.1 \pm 1.0$ & - \\
\hline & 1970-1985 & $-4.0 \pm 1.9$ & - & - & + & $-7.8 \pm 4.6$ \\
\hline & 1981-2000 & + & + & + & + & - \\
\hline & 1981-2013 & $6.1 \pm 0.9$ & $2.2 \pm 1.0$ & $9.4 \pm 2.2$ & $9.8 \pm 1.5$ & + \\
\hline \multirow[t]{7}{*}{ South all sky } & 1959-2013 & - & - & + & + & $-2.2 \pm 0.5$ \\
\hline & 1959-1985 & $-6.4 \pm 1.1$ & $-4.6 \pm 1.4$ & $-8.5 \pm 2.3$ & $-8.1 \pm 2.0$ & $-4.2 \pm 1.3$ \\
\hline & 1986-2013 & $6.0 \pm 1.2$ & + & $7.6 \pm 2.0$ & $13.5 \pm 2.3$ & + \\
\hline & 1970-2013 & $2.1 \pm 0.7$ & + & $3.7 \pm 1.2$ & $5.2 \pm 1.3$ & $-1.5 \pm 0.8$ \\
\hline & 1970-1985 & $-5.9 \pm 2.6$ & - & - & - & $-7.4 \pm \mathbf{3 . 0}$ \\
\hline & 1981-2000 & $5.0 \pm 1.9$ & $6.5 \pm 2.6$ & + & $9.3 \pm 3.5$ & $-2.4 \pm 1.7$ \\
\hline & 1981-2013 & $5.4 \pm 0.9$ & + & $6.9 \pm 1.7$ & $11.6 \pm 1.8$ & + \\
\hline \multirow[t]{7}{*}{ North clear sky estimated } & 1959-2013 & + & - & + & + & - \\
\hline & 1959-1985 & $-6.3 \pm 0.8$ & $-3.2 \pm 0.8$ & $-5.8 \pm 2.7$ & $-8.2 \pm 1.6$ & $-6.0 \pm 1.3$ \\
\hline & 1986-2013 & $7.6 \pm 0.9$ & $3.6 \pm 0.7$ & $9.7 \pm 1.6$ & $10.0 \pm 1.5$ & $6.5 \pm 1.3$ \\
\hline & 1970-2013 & $2.7 \pm 0.7$ & $0.9 \pm 0.4$ & $2.8 \pm 1.2$ & $5.1 \pm 0.9$ & $\mathbf{1 . 8} \pm \mathbf{0 . 8}$ \\
\hline & $1970-1985$ & $-5.7 \pm 1.5$ & - & - & $-6.9 \pm 2.4$ & $-7.5 \pm 2.7$ \\
\hline & 1981-2000 & $5.3 \pm 1.6$ & $3.2 \pm 1.4$ & + & $7.1 \pm 2.1$ & $5.3 \pm 2.3$ \\
\hline & 1981-2013 & $6.4 \pm 0.7$ & $2.7 \pm 0.6$ & $8.0 \pm 1.2$ & $9.3 \pm 1.1$ & $5.5 \pm 1.0$ \\
\hline \multirow[t]{7}{*}{ South clear sky estimated } & 1959-2013 & - & - & + & + & $-1.9 \pm 0.6$ \\
\hline & 1959-1985 & $-8.4 \pm 1.0$ & $-4.4 \pm 1.2$ & $-10.3 \pm 2.5$ & $-10.7 \pm 1.8$ & $-9.1 \pm 1.1$ \\
\hline & $1986-2013$ & $7.9 \pm 1.0$ & $3.9 \pm 1.3$ & $10.2 \pm 1.6$ & $11.4 \pm 1.9$ & $5.4 \pm 1.1$ \\
\hline & 1970-2013 & $2.8 \pm \mathbf{0 . 7}$ & $1.5 \pm 0.7$ & $4.2 \pm 1.2$ & $4.3 \pm 1.2$ & + \\
\hline & $1970-1985$ & $-8.1 \pm 1.8$ & - & $-11.3 \pm 5.2$ & $-11.8 \pm 3.3$ & $-10.2 \pm 2.1$ \\
\hline & 1981-2000 & $6.4 \pm 1.5$ & $7.2 \pm 2.3$ & $7.7 \pm 2.4$ & $10.7 \pm 2.5$ & + \\
\hline & 1981-2013 & $7.1 \pm 0.8$ & $3.7 \pm 1.0$ & $9.2 \pm 1.2$ & $10.7 \pm 1.5$ & $4.5 \pm 0.8$ \\
\hline
\end{tabular}

* Values are expressed in $\mathrm{W} \mathrm{m}^{-2}$ per decade. Values are shown in roman for a significance level of $0.05<p \leq 0.1$ and in bold for a significance level of $p \leq 0.05$. For non-significant trends, only the sign of the slope is given.

In order to give a more accurate information on the variations highlighted by Figs. 4 and 5, we estimated the trends in $\mathrm{W} \mathrm{m}^{-2}$ per decade for some key periods (Table 2), including 1959-2013 (the entire period covered by the records), 1959-1985 and 1986-2013 (the dimming and brightening periods according to the northern and southern Italy annual records), and other periods to allow a direct comparison with some relevant dimming/brightening papers (SanchezLorenzo et al., 2015; Wild, 2012). Specifically, we calculated the absolute series for each grid point by multiplying each seasonal/annual anomaly series obtained under all-sky conditions by the corresponding seasonal/annual normals, and then we calculated the seasonal and annual regional records by averaging all corresponding grid point absolute series. The seasonal/annual normals were calculated by averaging the corresponding monthly normals obtained using the same data and the procedure explained by Spinoni et al. (2012). In particular, the monthly normals were obtained starting from a database of SD normals for the Italian territory referring to flat and non-shaded sites. These normals were first transformed into SSR normals by means of the Ångström law and then interpolated onto the USGS GTOPO 30 digital elevation model grid (USGS, 1996) by means of an inverse distance Gaussian weighting spatialization model.

As previously shown, the trend over the whole period under analysis (1959-2013) is only significant in summer in the north $\left(+3.1 \mathrm{~W} \mathrm{~m}^{-2}\right.$ per decade $)$ and in autumn for both regions $\left(-1.5\right.$ and $-2.2 \mathrm{~W} \mathrm{~m}^{-2}$ for the north and the south, respectively). In the first case, considering the weak (and non-significant) dimming, the trend over the whole period is mostly driven by the increasing tendency of the second period, while in the second case, considering the weak brightening, the trend over the whole period is mostly driven by the decreasing tendency of the first period. Considering the 1959-1985 period, as the reference for the dimming period, the trend is significant in all the seasons for both the north 
and the south with values ranging between $-7.2 \mathrm{~W} \mathrm{~m}^{-2}$ per decade in spring and $-3 \mathrm{~W} \mathrm{~m}^{-2}$ per decade in winter for the north and between $-8.5 \mathrm{~W} \mathrm{~m}^{-2}$ per decade in spring and $-4.2 \mathrm{~W} \mathrm{~m}^{-2}$ per decade in autumn for the south. As concerns the brightening period, considering the 1986-2013 period, the trend is significant in all the seasons in the northern region with values ranging between $+3.2 \mathrm{~W} \mathrm{~m}^{-2}$ per decade in winter and $+12.3 \mathrm{~W} \mathrm{~m}^{-2}$ per decade in summer, while in the southern region it is only significant at an annual scale and during spring $\left(+7.6 \mathrm{~W} \mathrm{~m}^{-2}\right.$ per decade $)$ and summer $\left(+13.5 \mathrm{~W} \mathrm{~m}^{-2}\right.$ per decade).

\subsection{Trend analysis of the clear-sky SSR records}

The average northern and southern Italy seasonal and annual SSR records obtained under clear-sky conditions using 0 and 1 okta as thresholds to select the clear days are shown in Fig. 6 . The correlations between the records obtained with the two thresholds are between 0.86 for the spring season and 0.97 for the winter season in the north and between 0.87 for the winter and autumn season and 0.95 for the summer season in the south. The agreement increases if the correlation between the filters is considered (it is always higher than 0.96). The decadal variability shown by the trends using the two thresholds is very similar, with the exception of a few periods where one of the two records shows a higher interannual variability causing slight differences in the resulting trends. This is evident, for example, before the 1980s during the spring season in the north and during the winter season in the south; in both cases the 0 okta series shows higher variability than the 1 okta series. The difference in the resulting variability over the whole period under analysis (1959-2013) is particularly evident in the north, where it is always higher in the 0 okta than in the 1 okta series (the standard deviation of the residuals from the low-pass filter is between 0.02 and 0.04 for the 0 okta series and between 0.01 and 0.03 for the 1 okta series), while it is less evident in the south where the two series show the same variability (the standard deviation of the residuals from the low-pass filter is between 0.02 and 0.05 for both the thresholds). The advantage of 0 okta as the threshold is that it allows for only the real clear-sky conditions to be selected, but the limitation of this choice is that it only allows for a low number of days to be selected (in the north it is particularly due to the higher frequency of cloudy days), thereby increasing the variability in the obtained series. However, using 1 okta as the threshold allows for a more stable series to be obtained because it selects a higher number of days, which are, however, not completely clear.

In order to better understand the magnitude and the length of the tendencies shown in Fig. 6, we subjected the clear-sky records to a running trend analysis (Brunetti et al., 2006a), as previously illustrated for the all-sky series. The running trend obtained for the two different thresholds is very similar, so we show and discuss only the one obtained with 0 okta as the threshold (Fig. 7).
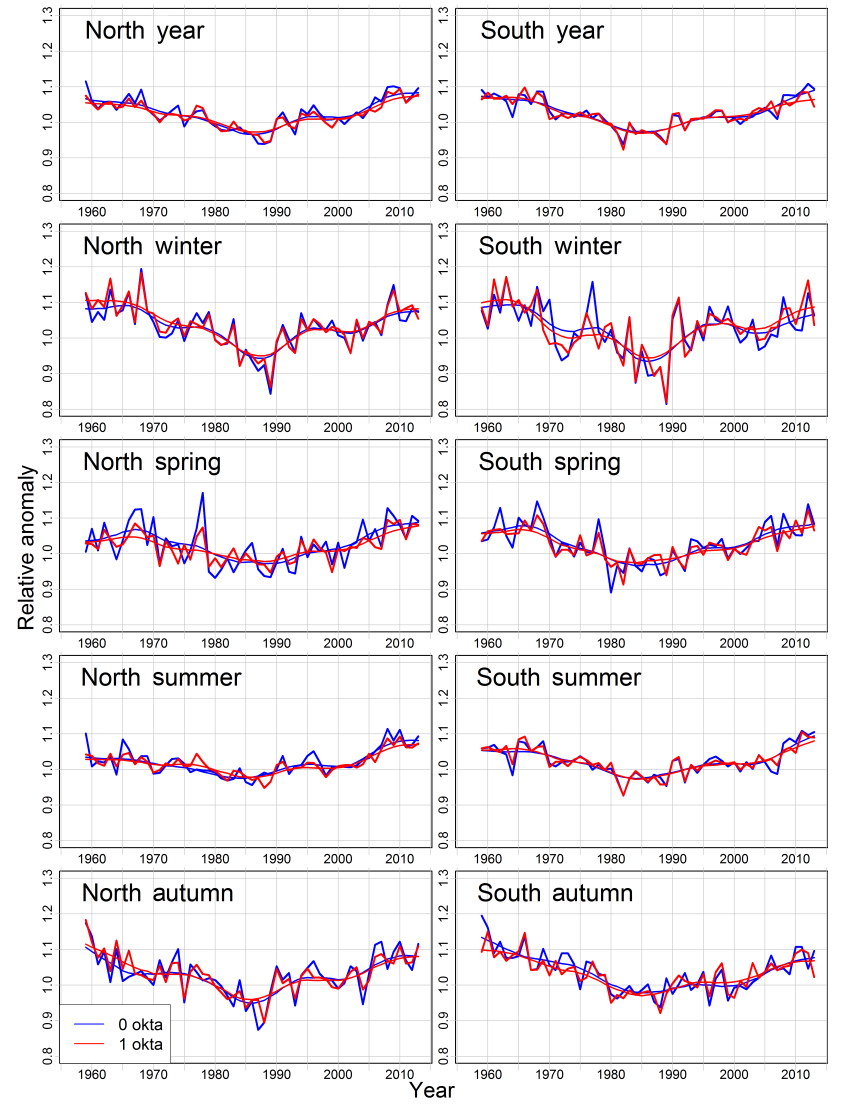

Figure 6. Average annual and seasonal northern (left column) and southern (right column) Italian SSR records obtained under clearsky conditions (bold lines), plotted together with an 11-year window, 3-year standard deviation Gaussian low-pass filter (thin lines). The series are expressed as relative deviations from the 1976-2005 means. The blue lines represent the records obtained using 0 okta of TCC as the threshold to select clear days and the red lines the ones using 1 okta.

At annual scale the clear-sky records show a comparable decreasing and following increasing tendency for both the north and the south as highlighted by the lack of a significant trend for the whole period under analysis (e.g., 1959-2013 period). However, the dimming period is slightly stronger in the southern region, especially if the sub-periods with fewer than 30 years and starting before the 1970s are considered (e.g., about $-4 \%$ per decade for the south and about $-3 \%$ per decade for the north for the 1961-1991 period), while the brightening period is slightly more intense in the northern region (e.g., about $+4 \%$ per decade for the north and about $+3 \%$ per decade for the south for the 1981-2011 period).

During the winter season, trends show a dimming and a subsequent brightening for both regions. The dimming is slightly stronger than the brightening and, as a consequence, the trend over almost the whole period under analysis is negative (e.g., $-2 \%$ per decade during the 1959-2009 for both regions). Records show a period of stabilization during the 


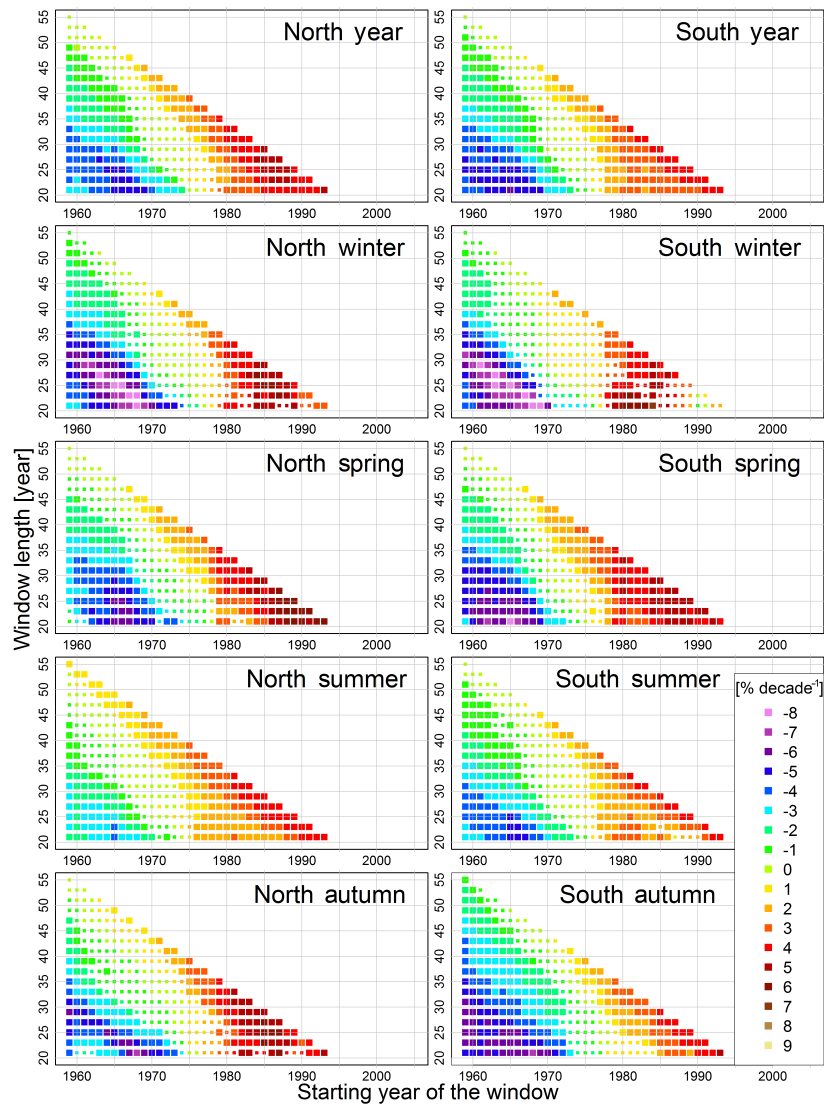

Figure 7. Running trend analysis for annual and seasonal northern (left column) and southern (right column) Italian SSR records obtained under clear-sky conditions ( 0 okta of TCC as the threshold). The $y$ and $x$ axes represent the length and the first year of the period under analysis, respectively, while the colored pixels show the trend expressed in $\%$ decade $^{-1}$ with a significance level of $p \leq 0.1$ (large squares) and $p>0.1$ (small squares).

mid-1970s and during the 2000s (Fig. 6), and so some subperiods, especially in the south, do not show a significant trend after the beginning of the 1980s.

The spring season has a similar pattern to the annual one with a clear negative-positive sequence after a starting period without any significant trend and a period of stabilization in the 1990s, for both northern and southern Italy. The dimming period is stronger in the south than in the north, where all the sub-periods with fewer than 30 years and starting before 1970 show a significant trend with values between $-8 \%$ per decade and $-3 \%$ per decade. However, the brightening period is slightly stronger in the north, especially after the mid-1980s, with values reaching $+6 \%$ per decade.

During the summer season the two regions show a different trend with a stronger dimming period in the south than in the north (e.g., about $-3 \%$ per decade for the south and about $-2 \%$ per decade for the north for the 1961-1991 period) and a stronger brightening period in the north, with all the sub-periods with fewer than 30 years showing a significant trend. Summer in the north is the only season that shows a significant positive trend for the longest window (e.g., $+1 \%$ per decade for the 1959-2013 period) while the summer season in the south, which shows a very similar behavior to the annual series, shows a negative trend for the windows that cover almost the whole period under analysis (e.g., $-2 \%$ per decade for the 1959-2009 period).

For the autumn season, trends show a decrease until the mid-1980s followed by an increase until the end of the series in both regions, even if in the north a period of stabilization is observed during 1970s, as already highlighted by the winter trend. The dimming period is stronger in the south than in the north (e.g., about $-5 \%$ per decade for the south and about $-4 \%$ per decade for the north for the 1961-1991 period), while the brightening is stronger in the north even if a period of stabilization is observed during 1990s, as already highlighted by the winter trend (e.g., about $+4 \%$ per decade for the north and about $+3 \%$ per decade for the south for the 1981-2011 period). Overall, in the northern region the trends of the two periods are comparable, while in the south the trend is stronger in the dimming period than in the brightening period, resulting in a significant negative trend over the whole period under analysis (e.g., about $-2 \%$ per decade for the 1959-2013 period).

\subsection{Comparison between all-sky and clear-sky SSR records}

In order to better investigate the differences between the trends illustrated in Sects. 3.1 and 3.2 and thus determine to what extent SSR variability depends on either cloud or aerosol variability, we compared the annual and seasonal low-pass filter series for all-sky and clear-sky conditions (considering 0 okta as the threshold) as shown in Fig. 8. For clarity, only filters of the time series are indicated.

The comparison between the trends obtained under the two different conditions shows that, without the contribution of clouds, dimming and brightening become more intense and significant in all seasons for both north and south. The differences are particularly evident during the winter and autumn seasons. Specifically, considering the winter season for both regions, the dimming period is more intense under clear-sky conditions than under all-sky conditions, with a significant trend for almost all sub-periods starting before the mid-1970s (see Figs. 5 and 7). As concerns the brightening period, in the northern region it is comparable under clear and all-sky conditions if the trend intensity is considered, while it presents some differences if curve shapes are taken into account. However, in the southern region the brightening becomes stronger and significant under clear-sky conditions even if a period of stabilization is evident in the mid-1990s. After removing cloud contribution, during the autumn season the length and intensity of dimming and brightening periods change for both regions. This is due to a shift in the trend 


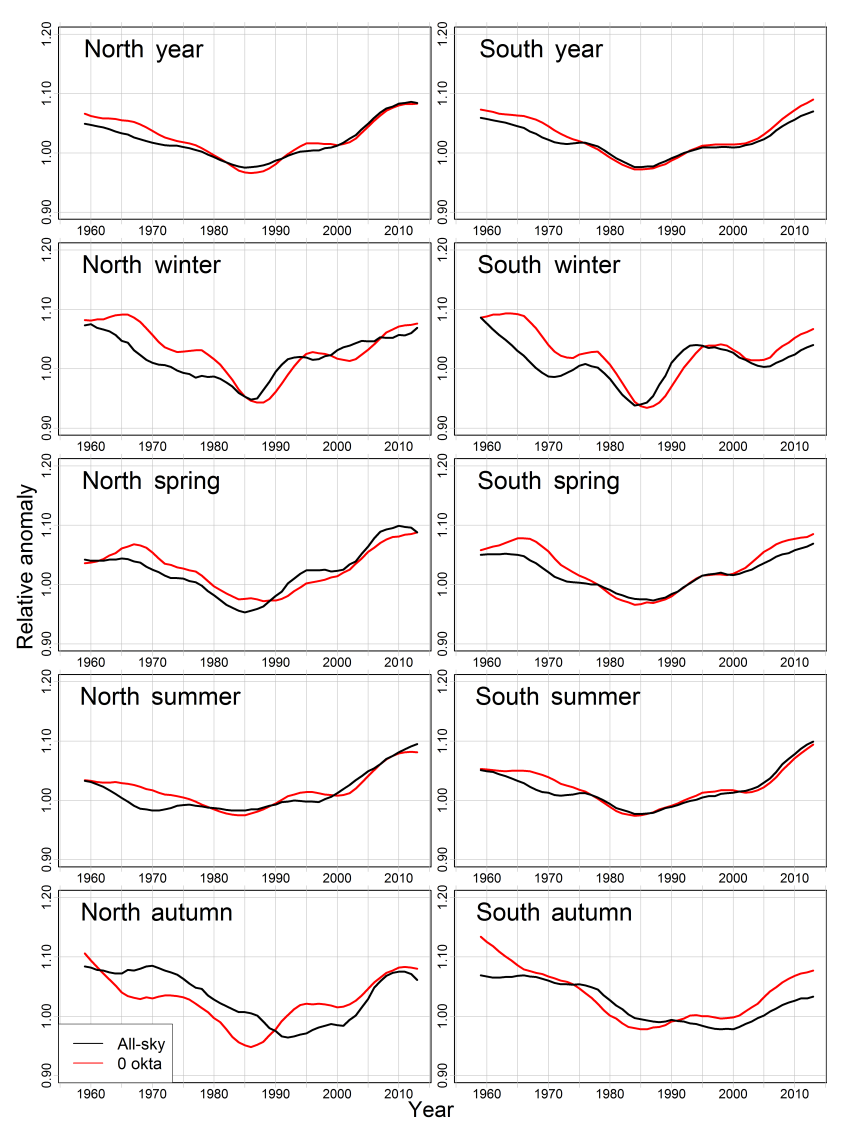

Figure 8. All-sky (black lines) and clear-sky 0 okta (red lines) SSR annual and seasonal low-pass filter for northern (left column) and southern (right column) Italy. The filters are the same as in Figs. 4 and 6 .

inversion from the beginning of the 1990s in the north and the end of the 1990s in the south to the mid-1980s as already observed for the other seasons for both all-sky and clear-sky conditions. This shift causes a shorter dimming period and a longer and more significant brightening period.

Differences between all-sky and clear-sky trends are less evident in spring and summer. Nevertheless, some differences are relevant in both seasons, especially during summer, in the north, where under all-sky conditions there is only a weak decrease, while it becomes more intense and significant under clear-sky conditions.

The differences between the all-sky and clear-sky anomaly records are also highlighted considering the ratios between the latter and the former records. Before 1980, low-pass filters applied to these ratios (figures not shown) show values higher than 1 in all seasons, with the only exception of autumn. Also, at annual scale, ratios are higher than 1 before about 1980, with maxima of 1.025 in the north (1967) and 1.024 in the south (1968) and a clear decrease in the 1970s. These results seem to suggest that, in Italy, global dimming has been partially hidden by a decreasing tendency of cloudiness and that without these changes in cloudiness the decrease in SSR in the dimming period would have been greater.

The comparison between clear-sky and all-sky anomaly records also allows for quantification of the effect of cloudiness on the observed SSR trends and thus the effect due to other factors. In this case, we have assumed that, if cloudiness did not change, clear-sky and all-sky anomaly records would have had the same behavior. With this hypothesis, virtual constant-cloudiness SSR trends were estimated by transforming, by means of the all-sky normals already presented in Sect. 3.1, the trends of the clear-sky anomaly records (obtained with $0 \mathrm{okta}$ as the threshold) into constant-cloudiness all-sky absolute trends. Trends expressed in $\mathrm{W} \mathrm{m}^{-2}$ per decade for the same periods considered in Table 2 for the all-sky series were calculated and the results are reported in the same table.

These values confirm what has already been highlighted by Fig. 8. Assuming no changes in cloudiness, at the annual scale the trend during the dimming period (19591985) decreases to $-6.3 \mathrm{~W} \mathrm{~m}^{-2}$ per decade in the north and $-8.4 \mathrm{~W} \mathrm{~m}^{-2}$ per decade in the south (the corresponding allsky trends are -4.4 and $-6.4 \mathrm{~W} \mathrm{~m}^{-2}$ per decade, respectively), confirming that the variations in cloudiness partially masked the all-sky decreasing trends. However, the influence of the cloudiness variability is not evident during the brightening period (1986-2013) in the north, where the all-sky and estimated constant-cloudiness records have almost the same trend, while it is more important in the south, where the trend increases from $+6.0 \mathrm{~W} \mathrm{~m}^{-2}$ per decade (all sky) to $+7.9 \mathrm{~W} \mathrm{~m}^{-2}$ per decade (estimated constant cloudiness). This behavior reflects the variations observed during winter, spring and summer. During autumn the cloudiness variability significantly influenced both periods and regions. In particular, during the brightening period the trend changes in the north from $+4.8 \mathrm{~W} \mathrm{~m}^{-2}$ per decade (all sky) to $+6.5 \mathrm{~W} \mathrm{~m}^{-2}$ per decade (estimated constant cloudiness) and in the south from a non-significant value (all sky) to $+5.4 \mathrm{~W} \mathrm{~m}^{-2}$ per decade (estimated constant cloudiness).

Without cloud contribution, the correlation between north and south becomes higher: the correlation coefficients range from 0.53 (winter) to 0.78 (year) under all-sky conditions and from 0.67 (autumn) to 0.86 (year) under clear-sky conditions. The largest variation is observed in winter, the season more affected by clouds, where the correlation coefficient increases from 0.53 (all sky) to 0.84 (clear sky), while the smallest variation is observed in summer, where the correlation coefficient changes from 0.74 (all sky) to 0.76 (clear sky). Under all-sky conditions the correlation between the two regions is higher in spring ( 0.64 for anomalies and 0.94 for filters) and summer (0.74 for anomalies and 0.89 for filters), while under clear-sky conditions the correlation is higher in winter ( 0.84 for anomalies and 0.96 for filters). 


\section{Discussion and conclusions}

A new dataset of long-term Italian SSR records has been set up for collecting data from different sources. Particular emphasis is placed upon the quality control and the homogenization of the records in order to ensure the reliability of the resulting trends, which can be affected by non-climatic signals. The majority of the inhomogeneities detected in the series happen before 1980, when many recalibrations, changes in instruments and station relocations occurred, while they become less relevant in the subsequent period. This is also highlighted by the Italian annual mean series, where the dimming observed in the homogenized series is not evident in the raw series during the 1960s and early 1970s, showing how, at a regional level, systematic biases in the original records can hide a significant part of the long-term trend.

Starting from the homogenized daily records, besides SSR series under all-sky conditions, SSR series under clear-sky conditions were also obtained by selecting clear days from corresponding ground-based TCC observations. Then, these series were projected onto a regular grid $\left(1^{\circ} \times 1^{\circ}\right)$ covering the entire Italian territory and clustered in two regions (northern and southern Italy) by means of a principal component analysis. The records of these areas were averaged in order to get the corresponding regional all-sky and clear-sky SSR records for the 1959-2013 period.

The clearest feature of the Italian all-sky SSR is a significant dimming from the beginning of the series to the mid1980s and a subsequent brightening until the end of the series for the annual mean, as well as during winter and spring in the northern region and spring and summer in the southern region. The trend over the whole period (1959-2013) is only significant during summer (positive) in the north and during autumn (negative) for both regions, as a consequence of a very weak dimming in the first case and a very weak brightening in the second case.

In the clear-sky SSR records, dimming and brightening trends become stronger, and they are significant for all seasons and for both regions. The strength of the clear-sky trends is higher than that observed for the all-sky records, especially during winter in the south and during summer in the north. The most evident differences between all-sky and clear-sky series are observed in autumn for both regions, where not only the variations become more intense and significant but also the change point from dimming to brightening moves from the mid-1990s to the mid-1980s. Thus, the fact that the change point under all-sky and clear-sky conditions differs by several years in autumn and the intensity of the two periods changes in all seasons supports the hypothesis that clouds contribute in a significant way to the SSR variability under all-sky conditions and confirms the hypothesis formulated by Manara et al. (2015) for SD, suggesting that cloud cover variations have partially masked the dimming caused by the increasing aerosol concentration, especially in the northern region. This is also confirmed by Maugeri et al. (2001), who found a highly significant negative trend in TCC all over Italy during the period 1951-1996.

The resulting trends without the contribution of the clouds show a more coherent pattern over the Italian territory. The peculiarities of a very weak dimming in summer for the north and a very weak brightening in winter for the south, as well as a strong and long dimming in autumn for both regions and the subsequent absence of brightening, are in fact attenuated under clear-sky conditions. The resulting trends under clear-sky conditions for both regions are in agreement with the changes in aerosol and aerosol precursor emissions that occurred during the period under analysis. More specifically, in Italy sulfur dioxide emissions, which can be converted to sulfate aerosols, show an increasing tendency until the 1980s due to the combustion of solid and liquid fuels (Mylona, 1996) and a decreasing tendency in the following years (Maggi et al., 2006; Vestreng et al., 2007). In parallel, the trends of black carbon and particulate organic matter show a change in tendency starting in the mid-1970s, which is earlier with respect to the sulfate aerosols due to the reduction in coal use in residential and commercial sectors as well as improved diesel engines (Novakov et al., 2003). Therefore, the combination of these trends could to some degree explain the SSR variability under clear-sky conditions, suggesting anthropogenic aerosols to be a relevant contributor of SSR variations in Italy under clear-sky conditions.

The dimming in the south in spring, summer and autumn is stronger than in the north under clear-sky, and this fact may challenge the above hypothesis as the north is more affected by air pollution due to higher emissions. Nevertheless, southern Italy is more affected by coarse aerosols (Bonasoni et al., 2004), causing a significant contribution of natural aerosols to SSR variability such as mineral dust intrusions from the Sahara and Sahel (Prospero, 1996). In particular, we highlight that a comparison between the northern and southern Italian clear-sky SSR variations and the Sahel precipitation index shows a good agreement, especially in southern Italy and during the Sahel rainy season (summer and autumn). The correlation coefficients between these two variables over the period 1959-2013 are 0.85 and 0.79 for the south and 0.74 and 0.79 for the north, respectively, for the summer and autumn seasons, suggesting a possible connection between SSR and Sahel precipitation index variability. Equally, they show a similar behavior with a decreasing tendency from the beginning of the series until the mid-1980s and an increasing tendency in the following period. The results are also coherent with the fact that mineral dust transportation from northern Africa into Europe shows a pronounced seasonal cycle with a maximum in summer and a minimum in winter (Pey et al., 2013; Varga et al., 2014) and a distinct gradient with the highest values near the northern coast of Africa (Gkikas et al., 2013; Prospero, 1996).

Long-term variations in dust transport into Europe are confirmed by measurements of dust accumulation in Alpine snow, which show a clear increase in mineral dust since the 
early 1970s, with quite high values after the 1980s. This suggests an increase in dust mobilization and transport from northern Africa to the north across the Mediterranean and into Europe (De Angelis and Gaudichet, 1991; Maggi et al., 2006) during the first part of the period covered by the SSR series. All this information supports the hypothesis that mineral dust contributes in a significant way to the SSR variability, with a higher contribution in the southern part of Italy than in the northern part, especially during summer and autumn. This could also explain why the summer correlation between the north and the south remains low even under clear-sky conditions, suggesting that cloud cover is not the cause of this low correlation, thus pointing to a different source, such as dust transport, that affects the two regions in a different way. However, the stronger dimming observed in the north during winter could be a consequence of higher concentrations of anthropogenic aerosols in that region with respect to the south. However, in order to confirm all these hypotheses on the role of natural and anthropogenic aerosols, there is a need for a better understanding of the factors influencing dust generation and transport, as well as a better understanding of the spatial distribution and temporal evolution of the different types of aerosols that characterize the atmosphere in northern and southern Italy.

It is also worth noticing that the time series, both for all-sky conditions and for clear-sky conditions, show relevant minima in some seasons in the periods 1982-1983 and 1992-1993, possibly as a consequence of the El Chichón (April 1982) and Pinatubo (June 1991) volcanic eruptions, which injected high amounts of sulfur dioxide into the stratosphere, causing a worldwide reduction in direct solar radiation (e.g., Robock, 2000; Sanchez-Lorenzo et al., 2009).

The observed trends under all-sky conditions are in good agreement with those observed in other worldwide areas and Europe. In particular, we compared the Italian trends with those obtained by Sanchez-Lorenzo et al. (2015), using a new version of the GEBA (Global Energy Balance Archive) dataset updated to 2012, for southern Europe. This comparison shows similar trends in the dimming period, while in the brightening period the trends are significantly stronger for Italy than for southern Europe. This is in agreement with the SD trends reported by Manara et al. (2015) for Italy, where the brightening, especially in the northern region, appeared to be stronger compared to Europe.

The all-sky SSR trends presented for the Italian territory show some discrepancies with respect to the trends of SD obtained for the same areas reported by Manara et al. (2015), despite the fact that the correlations between the two variables over the period 1959-2013 are between 0.71 in autumn and 0.88 in spring in the north and between 0.58 in autumn and 0.75 in spring in the south. The deviation of the SSR series with respect to the SD series is a trend reversal shifted from the mid-1980s to the beginning of the 1980s and a dimming period that is more intense and significant. The agreement between the two variables increases if the correlations between the residuals (ratio between the anomaly series and the filter) are considered; they are between 0.72 in summer and 0.91 in winter in the north and 0.62 at annual scale and 0.84 in spring for the south, highlighting a good year-to-year correlation between the two variables.

The fact that the dimming in SD is weaker than in SSR could indicate that the long-term increase in aerosols affects the two variables in a different way, inducing a more significant reduction in the intensity of SSR than in SD. The discrepancies between SSR and SD trends could also be a consequence of a different sensitivity to changes in the diurnal cycle and decadal variability of cloud cover, temperature and humidity that could modify the measurements of SD differently than SSR, but the reasons for these differences need further research. However, in a review, Sanchez-Romero et al. (2014) reported some studies that found similar discrepancies between SD and SSR trends in different areas of the world such as Germany (Power, 2003), China (Che et al., 2005; Zhang et al., 2004), the United States (Stanhill and Cohen, 2005) and the Canadian Prairies (Cutforth and Judiesch, 2007).

A more detailed understanding of the mechanisms driving the SSR variability in Italy under both all-sky and clear-sky conditions calls for further research including also the study of other variables such as temperature, visibility, aerosols and cloudiness.

\section{Data availability}

We received the Italian Air Force data ("Servizio dell'Aeronautica Militare Italiana") in the frame of an agreement between the Italian Air Force and the Italian National Research Council (for data access refer to http://clima.meteoam.it/istruzioni.php). In the frame of this agreement we also obtained the cloudiness data used to discriminate the clear days. For the BDAN ("Banca Dati Agrometeorologica Nazionale") data refer to http://cma.entecra.it/homePage.htm and for Trieste observatory refer to http://www.meteo.units.it/. The Swiss data were obtained from the Swiss Federal Office for Meteorology and Climatology (MeteoSwiss) and are available at http://www.meteosvizzera.admin.ch/ and https://gate.meteoswiss.ch/idaweb/login.do. The Sahel precipitation index data (doi:10.6069/H5MW2F2Q) came from the Joint Institute for the Study of the Atmosphere and Ocean and are available at http://research.jisao.washington.edu/data_sets/sahel/.

Acknowledgements. We gratefully thank all the institutions that allowed access to the data for research purposes and contributed to setting up the 1959-2013 surface solar radiation database. These are listed in the Sect. "Data availability" (websites and contact persons are provided for data access). Arturo Sanchez-Lorenzo was supported by a postdoctoral fellowship (JCI-2012-12508) 
and projects CGL2014-55976-R and CGL2014-52135-C3-1-R, financed by the Spanish Ministry of Economy and Competitiveness. We also kindly acknowledge Ruth Loewenstein for the help in improving the English.

Edited by: S. Kazadzis

Reviewed by: two anonymous referees

\section{References}

Aguilar, E., Auer, I., Brunet, M., Peterson, T. C., and Wieringa, J.: Guidelines on climate metadata and homogenization, World Climate Programme Data and Monitoring WCDMP-No. 53, WMOTD No. 1186, 50, 2003.

Albrecht, B. A.: Aerosols, cloud microphysics, and fractional cloudiness, Science, 245, 1227-1230, doi:10.1126/science.245.4923.1227, 1989.

Allen, R. J., Norris, J. R., and Wild, M.: Evaluation of multidecadal variability in CMIP5 surface solar radiation and inferred underestimation of aerosol direct effects over Europe, China, Japan, and India, J. Geophys. Res.-Atmos., 118, 6311-6336, doi:10.1002/jgrd.50426, 2013.

Alpert, P., Kishcha, P., Kaufman, Y. J., and Schwarzbard, R.: Global dimming or local dimming?: Effect of urbanization on sunlight availability, Geophys. Res. Lett., 32, L17802, doi:10.1029/2005GL023320, 2005.

Bonasoni, P., Cristofanelli, P., Calzolari, F., Bonafè, U., Evangelisti, F., Stohl, A., Zauli Sajani, S., van Dingenen, R., Colombo, T., and Balkanski, Y.: Aerosol-ozone correlations during dust transport episodes, Atmos. Chem. Phys., 4, 1201-1215, doi:10.5194/acp4-1201-2004, 2004.

Brunetti, M., Maugeri, M., Nanni, T., Auer, I., Böhm, R., and Schöner, W.: Precipitation variability and changes in the greater Alpine region over the 1800-2003 period, J. Geophys. Res.Atmos., 111, 1-29, doi:10.1029/2005JD006674, 2006a.

Brunetti, M., Maugeri, M., Monti, F., and Nanni, T.: Temperature and precipitation variability in Italy in the last two centuries from homogenised instrumental time series, Int. J. Climatol., 26, 345381, doi:10.1002/joc.1251, 2006b.

Che, H. Z., Shi, G. Y., Zhang, X. Y., Arimoto, R., Zhao, J. Q., Xu, L., Wang, B., and Chen, Z. H.: Analysis of 40 years of solar radiation data from China, 1961-2000, Geophys. Res. Lett., 32, L06803, doi:10.1029/2004GL022322, 2005.

Cherian, R., Quaas, J., Salzmann, M., and Wild, M.: Pollution trends over Europe constrain global aerosol forcing as simulated by climate models, Geophys. Res. Lett., 41, 2176-2181, doi:10.1002/2013GL058715, 2014.

Chiacchio, M. and Wild, M.: Influence of NAO and clouds on longterm seasonal variations of surface solar radiation in Europe, J. Geophys. Res., 115, D00D22, doi:10.1029/2009JD012182, 2010.

Craddock, J. M.: Methods of comparing annual rainfall records for climatic purposes, Weather, 34, 332-346, 1979.

Cutforth, H. W. and Judiesch, D.: Long-term changes to incoming solar energy on the Canadian Prairie, Agr. Forest Meteorol., 145, 167-175, doi:10.1016/j.agrformet.2007.04.011, 2007.
De Angelis, M. and Gaudichet, A.: Saharan dust deposition over Mont Blanc (French Alps) during the last 30 years, Tellus B, 43, 61-75, 1991.

Dutton, E. G., Stone, R. S., Nelson, D. W., and Mendonca, B. G.: Recent interannual variations in solar radiation, cloudiness, and surface temperature at the South Pole, J. Climate, 4, 848-858, 1991.

Dutton, E. G., Farhadi, A., Stone, R. S., Long, C. N., and Nelson, D. W.: Long-term variations in the occurrence and effective solar transmission of clouds as determined from surface-based total irradiance observations, J. Geophys. Res.-Atmos., 109, D03204, doi:10.1029/2003JD003568, 2004.

Dutton, E. G., Nelson, D. W., Stone, R. S., Longenecker, D., Carbaugh, G., Harris, J. M., and Wendell, J.: Decadal variations in surface solar irradiance as observed in a globally remote network, J. Geophys. Res.-Atmos., 111, 1-10, doi:10.1029/2005JD006901, 2006.

Folini, D. and Wild, M.: Aerosol emissions and dimming/brightening in Europe: Sensitivity studies with ECHAM5-HAM, J. Geophys. Res.-Atmos., 116, 1-15, doi:10.1029/2011JD016227, 2011.

Gilgen, H., Wild, M., and Ohmura, A.: Means and trends of shortwave irradiance at the surface estimated from global energy balance archive data, J. Climate, 11, 2042-2061, doi:10.1175/15200442-11.8.2042, 1998.

Gkikas, A., Hatzianastassiou, N., Mihalopoulos, N., Katsoulis, V., Kazadzis, S., Pey, J., Querol, X., and Torres, O.: The regime of intense desert dust episodes in the Mediterranean based on contemporary satellite observations and ground measurements, Atmos. Chem. Phys., 13, 12135-12154, doi:10.5194/acp-1312135-2013, 2013.

Hansen, J., Sato, M., and Ruedy, R.: Radiative forcing and climate response, J. Geophys. Res.-Atmos., 102, 6831-6864, doi:10.1029/96JD03436, 1997.

Hartmann, D. L., Ramanathan, V., Berroir, A., and Hunt, G. E.: Earth Radiation Budget Data and Climate Research, Rev. Geophys., 24, 439-468, 1986.

Italian Air Force: La radiazione solare globale e la durata del soleggiamento in Italia dal 1991 al 2010, Areonautica Militare, Reparto di Sperimentazione di Meteorologica Areonautica, 153, 2012.

Kvalevåg, M. M. and Myhre, G.: Human impact on direct and diffuse solar radiation during the industrial era, J. Climate, 20, 4874-4883, doi:10.1175/JCLI4277.1, 2007.

Li, Z., Xia, X., Cribb, M., Mi, W., Holben, B., Wang, P., Chen, H., Tsay, S.-C., Eck, T. F., Zhao, F., Dutton, E. G. and Dickerson, R. E.: Aerosol optical properties and their radiative effects in northern China, J. Geophys. Res. Atmos., 112, 1-11, doi:10.1029/2006JD007382, 2007.

Liang, F. and Xia, X. A.: Long-term trends in solar radiation and the associated climatic factors over China for 1961-2000, Ann. Geophys., 23, 2425-2432, doi:10.5194/angeo-23-2425-2005, 2005.

Liepert, B. and Tegen, I.: Multidecadal solar radiation trends in the United States and Germany and direct tropospheric aerosol forcing, J. Geophys. Res.-Atmos., 107, AAC 7-1-AAC 7-15, doi:10.1029/2001jD000760, 2002.

Liepert, B., Fabian, P., and Grassl, H.: Solar radiation in Germany - observed trends and an assessment of their causes. Part I: re- 
gional approach, Contributions to Atmospheric Physics, 67, 1529, 1994.

Liepert, B. G.: Observed reductions of surface solar radiation at sites in the United States and worldwide from 1961 to 1990, Geophys. Res. Lett., 29, 61-1-61-4, doi:10.1029/2002GL014910, 2002.

Lohmann, U. and Feichter, J.: Global indirect aerosol effects: a review, Atmos. Chem. Phys., 5, 715-737, doi:10.5194/acp-5-7152005, 2005.

Long, C. N. and Ackerman, T. P.: Identification of clear skies from broadband pyranometer measurements and calculation of downwelling shortwave cloud effects, J. Geophys. Res., 105, 1560915626, doi:10.1029/2000JD900077, 2000.

Long, C. N., Dutton, E. G., Augustine, J. A., Wiscombe, W., Wild, M., McFarlane, S. A., and Flynn, C. J.: Significant decadal brightening of downwelling shortwave in the continental United States, J. Geophys. Res., 114, D00D06, doi:10.1029/2008JD011263, 2009.

Maggi, V., Villa, S., Finizio, A., Delmonte, B., Casati, P., and Marino, F.: Variability of anthropogenic and natural compounds in high altitude-high accumulation alpine glaciers, Hydrobiologia, 562, 43-56, doi:10.1007/s 10750-005-1804-y, 2006.

Manara, V., Beltrano, M. C., Brunetti, M., Maugeri, M., SanchezLorenzo, A., Simolo, C., and Sorrenti, S.: Sunshine duration variability and trends in Italy from homogenized instrumental time series (1936-2013), J. Geophys. Res.-Atmos., 120, 3622-3641, doi:10.1002/2014JD022560, 2015.

Mateos, D., Sanchez-Lorenzo, A., Antón, M., Cachorro, V. E., Calbó, J., Costa, M. J., Torres, B., and Wild, M.: Quantifying the respective roles of aerosols and clouds in the strong brightening since the early 2000s over the Iberian Peninsula, J. Geophys. Res.-Atmos., 119, 10382-10393, doi:10.1002/2014JD022076, 2014.

Maugeri, M., Bagnati, Z., Brunetti, M. and Nanni, T.: Trends in Italian total cloud amount, 1951-1996, Geophysical Research Letters, 28(24), 4551-4554, doi:10.1029/2001GL013754, 2001.

Mylona, S.: Sulphur dioxide emissions in Europe 1880-1991 and their effect on sulphur concentrations and depositions, Tellus B, 48, 662-689, 1996.

Nabat, P., Somot, S., Mallet, M., Sanchez-Lorenzo, A., and Wild, M.: Contribution of anthropogenic sulfate aerosols to the changing Euro-Mediterranean climate since 1980, Geophys. Res. Lett., 41, 5605-5611, doi:10.1002/2014GL060798, 2014.

Nabat, P., Somot, S., Mallet, M., Sevault, F., Chiacchio, M., and Wild, M.: Direct and semi-direct aerosol radiative effect on the Mediterranean climate variability using a coupled regional climate system model, Clim. Dynam., 44, 1127-1155, doi:10.1007/s00382-014-2205-6, 2015.

Norris, J. R. and Wild, M.: Trends in aerosol radiative effects over Europe inferred from observed cloud cover, solar "dimming," and solar "brightening”, J. Geophys. Res., 112, D08214, doi:10.1029/2006JD007794, 2007.

Novakov, T., Ramanathan, V., Hansen, J. E., Kirchstetter, T. W., Sato, M., Sinton, J. E., and Sathaye, J. A.: Large historical changes of fossil-fuel black carbon aerosols, Geophys. Res. Lett., 30, 1324, doi:10.1029/2002GL016345, 2003.

Ohmura, A.: Observed decadal variations in surface solar radiation and their causes, J. Geophys. Res., 114, D00D05, doi:10.1029/2008JD011290, 2009.
Ohmura, A. and Lang, H.: Secular variation of global radiation in Europe, IRS'88: Current Problems In Atmospheric Radiation, edited by: Lenoble, J. and Geleyn, J.-F., A. Deepak Publ., Hampton, VA, 98-301, 1989.

Parding, K., Olseth, J. A., Dagestad, K. F., and Liepert, B. G.: Decadal variability of clouds, solar radiation and temperature at a high-latitude coastal site in Norway, Tellus B, 66, 25897, doi:10.3402/tellusb.v66.25897, 2014.

Pey, J., Querol, X., Alastuey, A., Forastiere, F., and Stafoggia, M.: African dust outbreaks over the Mediterranean Basin during 2001-2011: $\mathrm{PM}_{10}$ concentrations, phenomenology and trends, and its relation with synoptic and mesoscale meteorology, Atmos. Chem. Phys., 13, 1395-1410, doi:10.5194/acp-13-13952013, 2013.

Power, H. C.: Trends in solar radiation over Germany and an assessment of the role of aerosols and sunshine duration, Theor. Appl. Climatol., 76, 47-63, doi:10.1007/s00704-003-0005-8, 2003.

Preisendorfer, R. W.: Principal component analysis in meteorology and oceanography, Elsevier, New York, 1988.

Prospero, J. M.: Saharan dust transport over the North Atlantic Ocean and Mediterranean: An overview, The Impact of Desert Dust across the Mediterranean, Environ. Sci. Technol., 11, 133151, doi:10.1007/978-94-017-3354-0, 1996.

Radke, L. F., Coakley, J. A., and King, M. D.: Direct and remote sensing observations of the effects of ships on clouds, Science, 246, 1146-1149, doi:10.1126/science.246.4934.1146, 1989.

Ramanathan, V., Crutzen, P. J., Kiehl, J. T., and Rosenfeld, D.: Aerosols, Climate, and the Hydrological Cycle, Science, 294, 2119-2124, doi:10.1126/science.1064034, 2001.

Robock, A.: Vulcanic eruptions and climate, Rev. Geophys., 38, 191-219, doi:10.1029/1998RG000054, 2000.

Romanou, A., Liepert, B., Schmidt, G. A., Rossow, W. B., Ruedy, R. A., and Zhang, Y.: 20th Century Changes in Surface Solar Irradiance in Simulations and Observations, Geophys. Res. Lett., 34, doi:10.1029/2006GL028356, 2007.

Ruckstuhl, C. and Norris, J. R.: How do aerosol histories affect solar "dimming" and "brightening" over Europe?: IPCC-AR4 models versus observations, J. Geophys. Res., 114, D00D04, doi:10.1029/2008JD011066, 2009.

Ruckstuhl, C., Philipona, R., Behrens, K., Collaud Coen, M., Dürr, B., Heimo, A., Mätzler, C., Nyeki, S., Ohmura, A., Vuilleumier, L., Weller, M., Wehrli, C., and Zelenka, A.: Aerosol and cloud effects on solar brightening and the recent rapid warming, Geophys. Res. Lett., 35, L12708, doi:10.1029/2008GL034228, 2008.

Russak, V.: Trends of solar radiation, cloudiness and atmospheric transparency during recent decades in Estonia, Tellus B, 42, 206210, 1990.

Sanchez-Lorenzo, A. and Wild, M.: Decadal variations in estimated surface solar radiation over Switzerland since the late 19th century, Atmos. Chem. Phys., 12, 8635-8644, doi:10.5194/acp-128635-2012, 2012.

Sanchez-Lorenzo, A., Calbó, J., Brunetti, M., and Deser, C.: Dimming/brightening over the Iberian Peninsula: Trends in sunshine duration and cloud cover and their relations with atmospheric circulation, J. Geophys. Res., 114, D00D09, doi:10.1029/2008JD011394, 2009.

Sanchez-Lorenzo, A., Calbó, J., and Wild, M.: Global and diffuse solar radiation in Spain: Building a homogeneous dataset 
and assessing their trends, Global Planet. Change, 100, 343-352, doi:10.1016/j.gloplacha.2012.11.010, 2013.

Sanchez-Lorenzo, A., Wild, M., Brunetti, M., Guijarro, J. A., Hakuba, M. Z., Calbó, J., Mystakidis, S., and Bartok, B.: Reassessment and update of long-term trends in downward surface shortwave radiation over Europe (1939-2012), J. Geophys. Res.Atmos., 120, 9555-9569, doi:10.1002/2015JD023321, 2015.

Sanchez-Romero, A., Sanchez-Lorenzo, A., Calbó, J., González, J. A., and Azorin-Molina, C.: The signal of aerosolinduced changes in sunshine duration records: A review of the evidence, J. Geophys. Res.-Atmos., 119, 4657-4673, doi:10.1002/2013JD021393, 2014.

Sanchez-Romero, A., Sanchez-Lorenzo, A., González, J. A., and Calbó, J.: Reconstruction of long-term aerosol optical depth series with sunshine duration records, Geophys. Res. Lett., 43, 1296-1305, doi:10.1002/2015GL067543, 2016.

Sneyers, R.: On the use of statistical analysis for the objective determination of climate change, Meteorol. Z., 1, 247-256, 1992.

Spinoni, J., Brunetti, M., Maugeri, M., and Simolo, C.: 1961-1990 monthly high-resolution solar radiation climatologies for Italy, Adv. Sci. Res., 8, 19-25, doi:10.5194/asr-8-19-2012, 2012.

Stanhill, G.: The distribution of global solar radiation over the land surfaces of the Earth, Sol. Energy, 31, 95-104, 1983.

Stanhill, G. and Cohen, S.: Global dimming: A review of the evidence for a widespread and significant reduction in global radiation with discussion of its probable causes and possible agricultural consequences, Agr. Forest Meteorol., 107, 255-278, doi:10.1016/S0168-1923(00)00241-0, 2001.

Stanhill, G. and Cohen, S.: Solar Radiation Changes in the United States during the Twentieth Century?: Evidence from Sunshine Duration Measurements, Am. Meteorol. Soc., 18, 1503-1512, 2005.

Stanhill, G. and Moreshet, S.: Global radiation climate changes: The world network, Climatic Change, 21, 57-75, doi:10.1007/BF00143253, 1992.

Stravisi, F.: TRIESTE Dati orari di irradianza solare 1971-2003, Università degli Studi di Trieste-Dipartimento di Scienze della Terra Rapporti OM No. 105, 2004.

Stravisi, F. and Cirilli, S.: Irradianza solare globale 2013, Università degli Studi di Trieste-Dipartimento di Scienze della Terra, Rap no. 159, 2014.

Streets, D. G., Wu, Y., and Chin, M.: Two-decadal aerosol trends as a likely explanation of the global dimming/brightening transition, Geophys. Res. Lett., 33, L15806, doi:10.1029/2006GL026471, 2006.

Streets, D. G., Yan, F., Chin, M., Diehl, T., Mahowald, N., Schultz, M., Wild, M., Wu, Y., and Yu, C.: Anthropogenic and natural contributions to regional trends in aerosol optical depth, 1980 2006, J. Geophys. Res., 114, 1-16, doi:10.1029/2008JD011624, 2009

Turnock, S. T., Spracklen, D. V., Carslaw, K. S., Mann, G. W., Woodhouse, M. T., Forster, P. M., Haywood, J., Johnson, C. E., Dalvi, M., Bellouin, N., and Sanchez-Lorenzo, A.: Modelled and observed changes in aerosols and surface solar radiation over Europe between 1960 and 2009, Atmos. Chem. Phys., 15, $9477-$ 9500, doi:10.5194/acp-15-9477-2015, 2015.

Twomey, S. A., Piepgrass, M., and Wolfe, T. L.: An assessment of the impact of pollution on global cloud albedo, Tellus B, 36, 356366, doi:10.1111/j.1600-0889.1984.tb00254.x, 1984.
USGS: GTOPO 30 Digital Elevation Model, available at: https://lta. cr.usgs.gov/GTOPO30 (last access: September 2016), 1996.

Varga, G., Újvári, G., and Kovács, J.: Spatiotemporal patterns of Saharan dust outbreaks in the Mediterranean Basin, Aeol. Res., 15, 151-160, doi:10.1016/j.aeolia.2014.06.005, 2014.

Vestreng, V., Myhre, G., Fagerli, H., Reis, S., and Tarrasón, L.: Twenty-five years of continuous sulphur dioxide emission reduction in Europe, Atmos. Chem. Phys., 7, 3663-3681, doi:10.5194/acp-7-3663-2007, 2007.

Von Storch, H.: Spatial Patterns: EOFs and CCA, in Analysis of Climate Variability: Applications of Statistical Techniques, edited by: Navarra, A. and von Storch, H., Application of Statistical Techniques, 227-258, 1995.

Wang, K. C., Dickinson, R. E., Wild, M., and Liang, S.: Atmospheric impacts on climatic variability of surface incident solar radiation, Atmos. Chem. Phys., 12, 9581-9592, doi:10.5194/acp12-9581-2012, 2012.

Wang, Y. W. and Yang, Y. H.: China's dimming and brightening: evidence, causes and hydrological implications, Ann. Geophys., 32, 41-55, doi:10.5194/angeo-32-41-2014, 2014.

Wild, M.: Global dimming and brightening: A review, J. Geophys. Res., 114, D00D16, doi:10.1029/2008JD011470, 2009.

Wild, M.: Enlightening Global Dimming and Brightening, B. Am. Meteorol. Soc., 93, 27-37, doi:10.1175/BAMS-D-11-00074.1, 2012.

Wild, M.: Decadal changes in radiative fluxes at land and ocean surfaces and their relevance for global warming, WIREs Clim. Change, 7, 91-107, doi:10.1002/wcc.372, 2016.

Wild, M., Gilgen, H., Roesch, A., Ohmura, A., Long, C. N., Dutton, E. G., Forgan, B., Kallis, A., Russak, V., and Tsvetkov, A.: From Dimming to Brightening: Decadal Changes in Solar Radiation at Earth's Surface, Science, 308, 847-850, doi:10.1126/science.1103215, 2005.

Wild, M., Trüssel, B., Ohmura, A., Long, C. N., König-Langlo, G., Dutton, E. G., and Tsvetkov, A.: Global dimming and brightening: An update beyond 2000, J. Geophys. Res., 114, D00D13, doi:10.1029/2008JD011382, 2009.

Wilks, D. S.: Statistical methods in the atmospheric sciences, International Geophysics Series, 59, 464, 1995.

Xia, X.: A closer looking at dimming and brightening in China during 1961-2005, Ann. Geophys., 28, 1121-1132, doi:10.5194/angeo-28-1121-2010, 2010a.

Xia, X.: Spatiotemporal changes in sunshine duration and cloud amount as well as their relationship in China during 1954-2005, J. Geophys. Res.-Atmos., 115, 1-13, doi:10.1029/2009JD012879, 2010b.

Zhang, X., Xia, X., and Xuan, C.: On the drivers of variability and trend of surface solar radiation in Beijing metropolitan area, Int J. Climatol., 35, 452-461, doi:10.1002/joc.3994, 2015.

Zhang, Y. L., Qin, B. Q., and Chen, W. M.: Analysis of 40 year records of solar radiation data in Shanghai, Nanjing and Hangzhou in Eastern China, Theor. Appl. Climatol., 78, 217 227, doi:10.1007/s00704-003-0030-7, 2004.

Zhu, A., Ramanathan, V., Li, F., and Kim, D.: Dust plumes over the Pacific, Indian, and Atlantic oceans: Climatology and radiative impact, J. Geophys. Res.-Atmos., 112, 1-20, doi:10.1029/2007JD008427, 2007. 